This is the peer-reviewed version of the following article:

Fluorescence of methylated derivatives of hydroxyphenylimidazopyridine.

Resolution of strongly overlapping spectra and a new ESIPT dye showing very efficient radiationless deactivation

Alfonso Brenlla, Manoel Veiga, M. Carmen Ríos Rodríguez, Manuel Mosquera and Flor Rodríguez-Prieto

Photochem. Photobiol. Sci., 2011, 10, 1622. DOI: 10.1039/c1pp05165b, which has been published in final form at http://pubs.rsc.org/en/content/articlelanding/2011/pp/c1pp05165b

This article may be used for non-commercial purposes only. 


\title{
Fluorescence of methylated derivatives of hydroxyphenylimidazo- pyridine. Resolution of strongly overlapping spectra and a new ESIPT dye showing very efficient radiationless deactivation
}

\author{
Alfonso Brenlla, ${ }^{a}$ Manoel Veiga, ${ }^{a}$ M. Carmen Ríos Rodríguez, ${ }^{* a}$ Manuel Mosquera ${ }^{* a}$ and Flor Rodríguez- \\ Prieto $^{* a}$
}

Received (in XXX, XXX) Xth XXXXXXXXX 200X, Accepted Xth XXXXXXXXX 200X

First published on the web $X t h X X X X X X X X X 200 X$

DOI: 10.1039/b000000x

The ground- and excited-state behaviour of the isomeric species 2-(2'-methoxyphenyl)imidazo

10 [4,5-b]pyridine (1-OMe) and 2-(2'-hydroxyphenyl)-4-methylimidazo[4,5-b]pyridine (1-NMe) in neutral and acid media has been studied by UV-vis absorption spectroscopy, steady-state and timeresolved fluorescence spectroscopy. The new dye 1-NMe is non-fluorescent in neutral media except in trifluoroethanol, where it shows a very weak fluorescence. 1-NMe exhibits also highly solvent-dependent fluorescence intensity in acidic media. We propose that the neutral species 15 experiences a fast excited-state intramolecular proton transfer (ESIPT), relaxing afterwards by intramolecular twisting associated with internal charge transfer (TICT) and subsequent very fast internal conversion of the proton-transferred TICT structure. The behaviour of 1-NMe in acidic media is explained by the existence of a ground-state tautomeric equilibrium between species with intramolecular hydrogen bonds $\mathrm{N}-\mathrm{H} \cdots \mathrm{OH}$ and $\mathrm{N} \cdots \mathrm{H}-\mathrm{O}$. The first type of tautomers dissociates at 20 the hydroxyl group in water and ethanol, but fluoresces in acetonitrile and trifluoroethanol due to the inability of these solvents to accept the proton. The second type of tautomers is non-emissive due to fast radiationless deactivation through an ESIPT-TICT process. The fluorescence of 1-OMe was investigated in neutral and acidic media, demonstrating the photobasic character of the pyridine nitrogen. A ground-state equilibrium between pyridinium and imidazolium cations was

${ }_{25}$ found for this species, showing overlapping absorption and fluorescence spectra. We devised a method to resolve the spectra by applying principal component global analysis to a series of excitation spectra taken at different emission wavelengths, which allowed estimation of the equilibrium constant between the cations.

\section{${ }_{30}$ 1. Introduction}

Among the various intramolecular processes induced by light absorption, the excited-state intramolecular proton transfer $(\mathrm{ESIPT})^{1-5}$ and the intramolecular charge transfer (ICT) ${ }^{6,7}$ lie at the heart of many photochemical and photobiological 35 processes. A special case of ICT processes are those leading to twisted structures (twisted intramolecular charge-transfer states, or TICT states), which are commonly encountered for a wide variety of molecular species. ${ }^{7,8}$ The widespread interest in ESIPT and ICT processes encompass fundamental studies 40 of intramolecular processes ${ }^{1-10}$ and applications as sensors in biological and chemical systems ${ }^{11-15}$ or as advanced devices for lasing, optical storage and electroluminescence. ${ }^{16-18}$

The interplay between intramolecular proton- and chargetransfer processes is a topic of long-standing research 45 interest, ${ }^{19-36}$ related to the more general subject of protoncoupled electron transfer. ${ }^{6,37,38}$ In this paper, we study a pair of isomeric species (see Fig. 1) that may experience ESIPT and TICT processes.

Many ESIPT and TICT molecules are well known by their
50

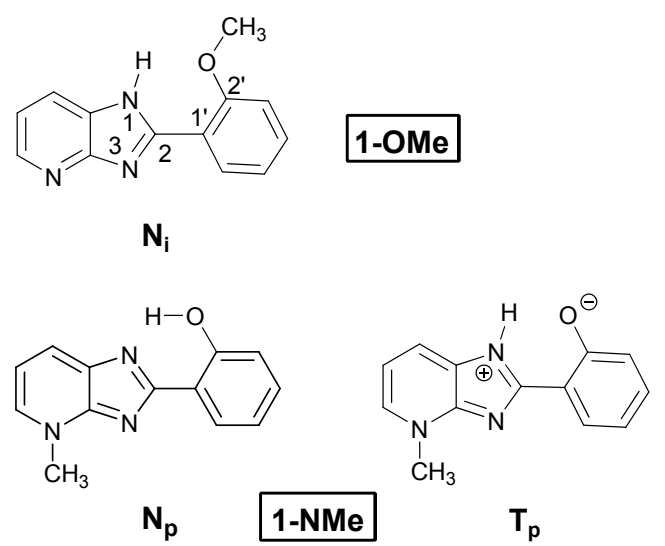

Fig. 1 Molecular structures of the compounds studied in this work, 1-OMe and 1-NMe. The normal forms $\left(\mathbf{N}_{\mathbf{i}}\right.$ and $\left.\mathbf{N}_{\mathrm{p}}\right)$ and the tautomer $\mathbf{T}_{\mathbf{p}}$ obtained for 1-NMe after ESIPT are shown. Subscript $\mathbf{i}$ indicates that a $\mathrm{H}$ atom is bonded to an imidazole $\mathrm{N}$, whereas subscript $\mathbf{p}$ 55 designates the structure with a hydrogen or methyl group attached to the pyridine $\mathrm{N}$. 
ability to act as very efficient UV absorbers, used for photoprotection in sunscreens and polymer photostabilizers. ${ }^{28,}$ 39, 40 It has long been known for ESIPT molecules that the photoprotection efficiency depends on an intact $s$ intramolecular hydrogen bond, essential for the ultrafast intramolecular proton transfer in the excited state. ${ }^{40}$ The phototautomer produced in the ESIPT process undergoes a fast radiationless deactivation which transforms the absorbed radiation energy into innocuous thermal energy, providing the 10 basis for the photoprotective activity.

The involvement of a large-amplitude motion ${ }^{28-36,41-52}$ and an intramolecular charge-transfer process ${ }^{28-36,47-49,51}$ in the fast radiationless deactivation of several ESIPT phototautomers has been reported by several authors. In 15 favourable cases, the emission of an ICT state was detected. ${ }^{25-}$ $27 \mathrm{We}$ and others proposed that the efficient radiationless deactivation of the proton-transferred phototautomer is often connected with the capacity of this species to form a TICT state, which decays at ultrafast rate. ${ }^{31-36,47-49}$ The efficiency of 20 the TICT process depends, in turn, on the facility to achieve twisted structures ${ }^{28,33,35,49}$ and on the strength of the electron donor (deprotonated moiety) and electron acceptor (protonated moiety) of the phototautomer. Electronwithdrawing groups introduced in the protonated moiety, or

25 electron-donating groups introduced in the deprotonated moiety, facilitate therefore the TICT process, with concomitant enhancement of the radiationless deactivation and photoprotector efficiency. ${ }^{28,29,35,49,53}$ On the contrary, electron-withdrawing substituents introduced in the 30 deprotonated moieties of several ESIPT molecules decrease the rate of the radiationless deactivation and increase consequently their fluorescence quantum yields. ${ }^{53}$ Various authors have stressed the relevance of this knowledge for the design of new ESIPT dyes useful as UV absorbers or 35 fluorescent probes. ${ }^{28,53}$

As mentioned above, a key factor that modulates the efficiency of the TICT process of the proton-transferred phototautomer is the strength of the electron donor and electron acceptor. For example, no experimental evidence for 40 TICT deactivation was found for the phototautomer of 2-(2'hydroxyphenyl)benzimidazole (HBI), ${ }^{35}$ but its derivatives bearing a better electron donor (an amino or dialkylamino group at C4') were found to undergo a fast radiationless deactivation, which was interpreted as a coupled ESIPT-TICT ${ }^{45}$ process. ${ }^{49}$ To further test this model, we investigate in this work the ground- and excited-state behaviour of the HBI derivatives 1-OMe and 1-NMe (see Fig. 1). The last species may undergo an ESIPT process, giving rise to the protontransferred phototautomer $\mathbf{T}_{\mathbf{p}}$ from the normal form $\mathbf{N}_{\mathbf{p}}$. On

50 the contrary, its isomer 1-OMe is unable to undergo ESIPT, as it lacks the hydroxyl hydrogen, but both 1-OMe and 1-NMe could in turn experience a TICT process. Given that the imidazopyridine moiety of these molecules possesses higher electron-acceptor ability than the benzimidazole moiety of ${ }_{55} \mathrm{HBI}$, we expect the TICT process to be enhanced for 1-OMe and 1-NMe. Quantum-mechanical calculations already predicted an ESIPT-TICT process for related azo derivatives of HBI, ${ }^{50}$ and dual emission due to a TICT process was demonstrated for 2-(4'-N,N-dimethylamino)phenylimidazo $60[4,5-b]$ pyridine..$^{54,55}$

In this paper, we elucidate the ground-state equilibria and the excited-state proton- and charge-transfer processes of 1-NMe and 1-OMe, in different solvents and acidity conditions. To the best of our knowledge, 1-NMe is a new ${ }_{6}$ species which has not been described before. 1-OMe was previously prepared and its therapeutic effects demonstrated. ${ }^{56-58}$ The photophysical behaviour of 1-OMe was investigated by Dogra et al. in several solvents at various acidities by means of absorption and fluorescence 70 spectroscopy and semi-empirical quantum mechanical calculations. ${ }^{59}$ The work reported herein extends the knowledge of the behaviour of this species. We devised a method for resolving the strong overlapping absorption and fluorescence spectra of the imidazolium and pyridinium 75 cations found in equilibrium for 1-OMe. This allowed us to estimate the ground-state equilibrium constant between them. Moreover, we were able to demonstrate the photobasic character of the pyridine nitrogen of 1-OMe in the excited state.

\section{so 2. Experimental}

\subsection{Synthesis and characterization}

The compounds investigated in this work were prepared by the double condensation of a diamine and a carboxylic acid: 2,3-diaminopyridine and 2-methoxybenzoic acid (Aldrich) for 85 1-OMe and 1-methyl-2-imino-1,2-dihydro-3-pyridinamine and salicylic acid for 1-NMe. Polyphosphoric acid (Merck) was used as solvent and catalyst. The reaction mixture was heated to $160-180^{\circ} \mathrm{C}$ for 2 hours and the final products were washed with water several times and recrystallized from 90 ethanol-water (50:50). 1-methyl-2-imino-1,2-dihydro-3pyridinamine was synthesized as follows: 2,3-diaminopyridine was heated to $60{ }^{\circ} \mathrm{C}$ for 1 minute in acetic anhydride (Aldrich) to yield 2,3-pyridinedicarbamic acid, which was refluxed for 4 hours in ethanol with an excess of methyl iodide (Aldrich). 95 The reaction product, 2,3-bis(carboxyamino)-1methylpyridinium iodide, was then heated to $90^{\circ} \mathrm{C}$ in $1 \mathrm{M}$ hydrochloric acid for 40 minutes. The reaction mixture was basified with $\mathrm{Na}_{2} \mathrm{CO}_{3}$ and the solid precipitate obtained (1methyl-2-imino-1,2-dihydro-3-pyridinamine) was filtered and 100 washed. The structure of the new compound 1-NMe was confirmed by high-resolution mass spectrometry (ESI-TOF; $m / z$ : calculated for $\mathrm{C}_{13} \mathrm{H}_{12} \mathrm{~N}_{3} \mathrm{O}^{+}\left([\mathrm{M}+\mathrm{H}]^{+}\right)$226.0980, found 226.0979) and by ${ }^{1} \mathrm{H}-\mathrm{NMR}\left(300 \mathrm{MHz}\right.$; dimethyl sulfoxide- $\mathrm{d}_{6}$; $\left.\mathrm{Me}_{4} \mathrm{Si}\right), \delta /$ ppm: $4.30(3 \mathrm{H}, \mathrm{s}), 6.92(1 \mathrm{H}, \mathrm{t}, \mathrm{J}=7.82 \mathrm{~Hz}), 6.94$ $105(1 \mathrm{H}, \mathrm{d}, \mathrm{J}=7.82 \mathrm{~Hz}) 7.30(2 \mathrm{H}, \mathrm{m}), 8.28(3 \mathrm{H}, \mathrm{m})$

The spectral properties of synthesized 1-OMe compare favourably with those previously described for this compound. ${ }^{59}{ }^{1} \mathrm{H}-\mathrm{NMR}$ of 1-OMe (300 MHz, dimethyl sulfoxide $\left.-\mathrm{d}_{6} ; \mathrm{Me}_{4} \mathrm{Si}\right), \delta(\mathrm{ppm}): 3.95(\mathrm{~s}, 1.2 \mathrm{H}), 4.02(\mathrm{~s}, 1.8 \mathrm{H})$, $1107.05-7.28(\mathrm{~m}, 3.4 \mathrm{H}), 7.5(\mathrm{~m}, 1 \mathrm{H}), 7.92(\mathrm{dd}, 0.5 \mathrm{H}, \mathrm{J}=1.42$ $\mathrm{Hz}, \mathrm{J}=7.82 \mathrm{~Hz}), 8.02(\mathrm{~d}, 0.3 \mathrm{H}, \mathrm{J}=7.82 \mathrm{~Hz}), 8.20(\mathrm{~d}, 0.3 \mathrm{H}$, $\mathrm{J}=7.82 \mathrm{~Hz}), 8.30(\mathrm{~m}, 1.6 \mathrm{H})$. The NMR spectrum reveals that 1-OMe experiences a slow tautomeric equilibrium in dimethyl sulfoxide. Detailed data for this equilibrium was obtained by 


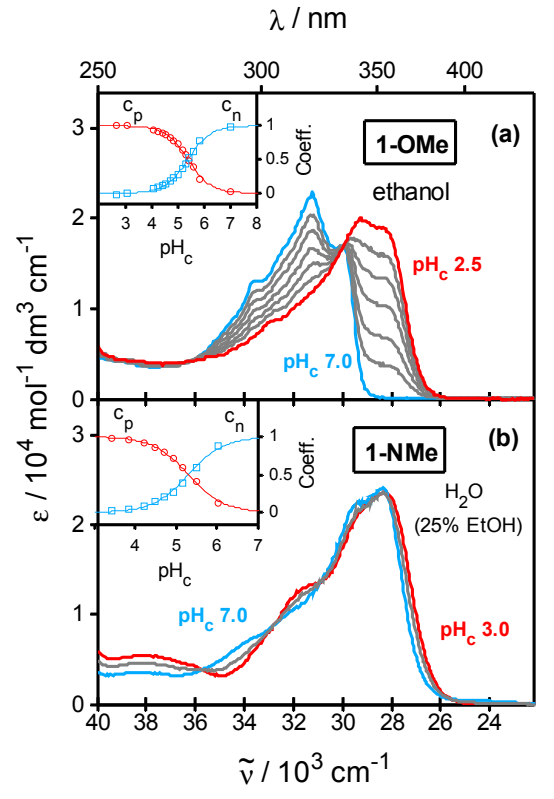

Fig. 2 (a) Absorption spectra of 1-OMe in ethanol at various $\mathrm{pH}_{\mathrm{c}}$ values between 2.5 and $7.0,[1-\mathbf{O M e}]=4.58 \times 10^{-5} \mathrm{~mol} \mathrm{dm}^{-3}$. (b) Absorption spectra of 1-NMe in water ( $25 \%$ ethanol) at various $\mathrm{pH}_{\mathrm{c}}$ values between 3.0 and 7.0, $[\mathbf{1}-\mathrm{NMe}]=3.52 \times 10^{-5} \mathrm{~mol} \mathrm{dm}^{-3}$. The 5 insets show the experimental (symbols) and calculated (solid lines) acidity-dependent contributions of the protonated $\left(c_{p}\right)$ and neutral $\left(c_{n}\right)$ species.

Barraclough et al..$^{60}$ for the closely related species 2-(2',4'10 dimethoxyphenyl)imidazo[4,5- $b]$ pyridine in the same solvent A comprehensive ${ }^{13} \mathrm{C}$ NMR investigation led these authors to conclude that a slow $1 H-3 H$ tautomerism with concomitant rotation about the $\mathrm{C}(2)-\mathrm{C}\left(1^{\prime}\right)$ bond takes place, giving rise to the equilibrium of the two intramolecularly hydrogen-bonded

15 tautomers $\mathrm{N}-\mathrm{H} \cdots \mathrm{OCH}_{3}$ in $2: 1$ proportion, favouring the $1 \mathrm{H}-$ tautomer. As judged by the relative intensities of the ${ }^{1} \mathrm{H}-\mathrm{NMR}$ signals assigned to the methoxy group of 1-OMe (1.8:1.2), the tautomers ratio would be $(1.5: 1)$ for this species in dimethy sulfoxide. The rate of tautomerisation was found to be much 20 faster in $\mathrm{D}_{2} \mathrm{O}{ }^{60}$

\subsection{Methods}

Solutions were made up in double-distilled water treated with $\mathrm{KMnO}_{4}$ and in spectroscopy-grade solvents. Aqueous solutions always contained $25 \%(\mathrm{v} / \mathrm{v})$ ethanol, due to the low 25 solubility of the compounds in pure water. Acidity was varied with $\mathrm{HClO}_{4}$ (Fluka, 60\%) in acetonitrile (Scharlau, 99.9\%) and ethanol (Scharlau, 99.9\%), and with $\mathrm{NaOH}$ (Fluka, 98\%), $\mathrm{HClO}_{4}$ and acetic acid/sodium acetate (Scharlau, 99.8\%) or ammonium perchlorate/ammonia (Fluka, 98\%) buffers in 30 aqueous solutions. In all the solvents, $\mathrm{pH}_{\mathrm{c}}$ was calculated as $-\log \left(\left[\mathrm{H}^{+}\right] / \mathrm{mol} \mathrm{dm}^{-3}\right)$. All experiments were carried out at 20 ${ }^{\circ} \mathrm{C}$ and the solutions were not degassed.

UV-Vis absorption spectra were recorded in a Varian Cary $3 \mathrm{E}$ spectrophotometer. Fluorescence excitation and emission 35 spectra were recorded in a Jobin Yvon-Spex Fluoromax-2 spectrofluorometer, with correction for instrumental factors by means of a reference photodiode and correction files supplied by the manufacturer. Sample concentrations of $\sim 10^{-5}$ mol dm${ }^{-3}$ for absorption and $\sim 10^{-6} \mathrm{~mol} \mathrm{dm}^{-3}$ for fluorescence 40 were employed. Fluorescence quantum yields were measured using quinine sulphate $\left(<3 \times 10^{-5} \mathrm{~mol} \mathrm{dm}^{-3}\right)$ in aqueous $\mathrm{H}_{2} \mathrm{SO}_{4}\left(0.5 \mathrm{~mol} \mathrm{dm}{ }^{-3}\right)$ as standard $(\Phi=0.546) .{ }^{61},{ }^{62}$ Fluorescence lifetimes were determined by single-photon timing in an Edinburgh Instruments LifeSpec-ps spectrometer 45 provided with three excitation sources: one diode laser at 375 $\mathrm{nm}$ and two light-emitting diodes (LEDs) at $333 \mathrm{~nm}$ and 308 $\mathrm{nm}$. The equipment time resolution was $\sim 20 \mathrm{ps}$ with the diode laser and $\sim 50 \mathrm{ps}$ with the LEDs.

Model equations were fitted to the experimental data using 50 a nonlinear weighted least-squares algorithm. All the data analysis (simple equation fitting, decay traces reconvolution and principal component global analysis) was performed with laboratory-made routines deployed in Matlab 7.5.0 for Windows. Taking into account all the experimental error 55 sources, the standard uncertainty was estimated to be around $0.05 \mathrm{~ns}$ for the fluorescence decay times, $10 \%$ for the fluorescence quantum yields and 0.10 for ground-state $\mathrm{pK}_{\mathrm{a}}$ measurements.

\section{Results}

\section{${ }_{60} 3.1$ Absorption spectra}

The absorption spectra of 1-OMe in ethanol at several acidities are shown in Fig. 2 (a). The absorption spectrum obtained under neutral conditions presented vibronic structure and peaked at $31300 \mathrm{~cm}^{-1}$. Upon increasing the acidity, the ${ }_{65}$ spectra lost some vibronic structure and shifted to the red, the new maximum with similar intensity being located at 29500 $\mathrm{cm}^{-1}$. The spectral characteristics observed for 1-OMe in aqueous solution and ethanol were very alike.

Fig. 2 (b) shows some absorption spectra recorded for 70 1-NMe in neutral-to-acid aqueous solution with $25 \%$ ethanol. The absorption spectrum in neutral medium presented its maximum at $28330 \mathrm{~cm}^{-1}$. Acidification of the solution produced only a very slight change in the absorption spectrum, its maximum in acidic medium being located at $7528250 \mathrm{~cm}^{-1}$. The absorption spectra of 1-NMe in ethanol and water were very alike.

\subsection{Fluorescence spectra and lifetimes in neutral media}

The absorption and fluorescence spectra of 1-OMe in acetonitrile, ethanol, cyclohexane, and water with $25 \%$ 80 ethanol were very similar, structured, and independent of the monitoring wavenumber (see the spectra in Fig. 3 (a) and (b) as representative examples). The fluorescence quantum yields were found to be quite high in all the solvents studied (Table 1). The fluorescence decay of 1-OMe was monoexponential in 85 the solvents just mentioned, the lifetime increasing in the series cyclohexane $<$ acetonitrile $<$ ethanol $<$ water (Table 2).

The absorption spectrum of 1-OMe in trifluoroethanol was very similar to that obtained in other solvents, but the fluorescence spectrum was very different, showing dual 90 fluorescence (see panel (c) of Fig. 3). The normal Stokesshifted band was very alike to the only band observed in other 


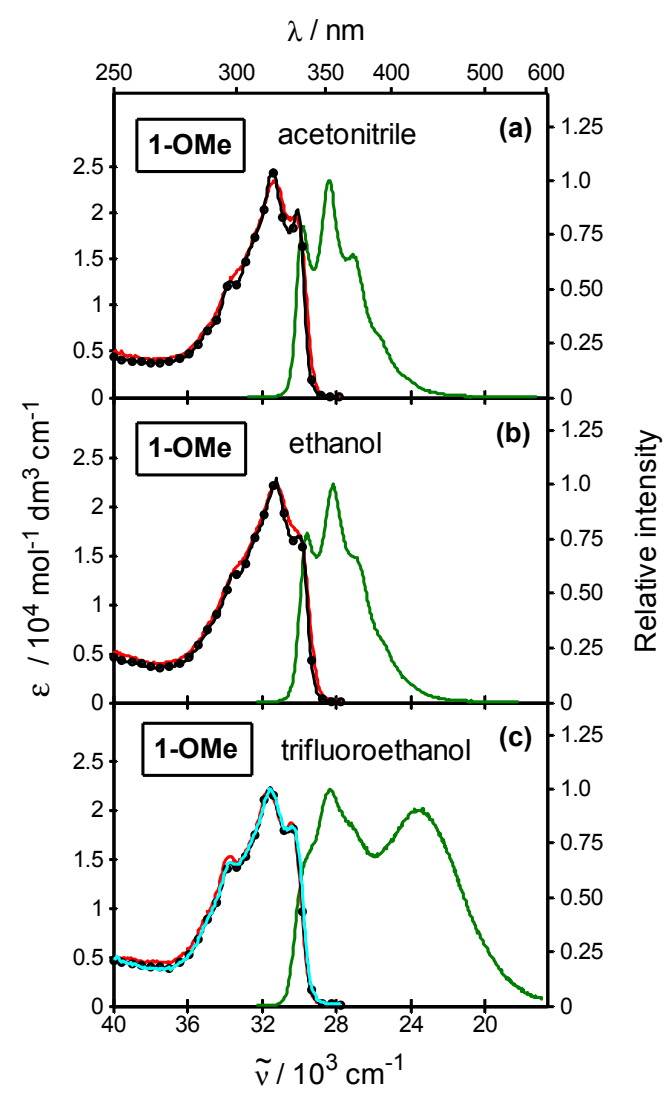

Fig. 3 Absorption spectra $(-\bullet)$ and normalized fluorescence emission and excitation spectra of 1-OMe in (a) acetonitrile, $\tilde{v}_{\text {exc }}=$ $33330 \mathrm{~cm}^{-1}(-), \tilde{v}_{e m}=25640 \mathrm{~cm}^{-1}(-)$, (b) ethanol, $\tilde{v}_{\text {exc }}=30300$ $\mathrm{cm}^{-1}(-), \tilde{v}_{e m}=27030 \mathrm{~cm}^{-1}(-)$, and (c) trifluoroethanol, $\tilde{v}_{\text {exc }}=$ s $30300 \mathrm{~cm}^{-1}(-), \tilde{v}_{e m}=27780 \mathrm{~cm}^{-1}(-), \tilde{v}_{e m}=22220 \mathrm{~cm}^{-1}(-)$.

Table 1 Fluorescence quantum yields of 1-OMe and 1-NMe in various solvents at $298 \mathrm{~K}$. The excitation wavenumbers are shown in parentheses

\begin{tabular}{|c|c|c|}
\hline Solvent & $\Phi_{\mathrm{F}}[1-\mathrm{OMe}]$ & $\Phi_{\mathrm{F}}[1-\mathrm{NMe}]$ \\
\hline \multicolumn{3}{|c|}{ neutral media } \\
\hline cyclohexane & - & very low \\
\hline acetonitrile & $0.48\left(31750 \mathrm{~cm}^{-1}\right)$ & very low \\
\hline ethanol & $0.56\left(31750 \mathrm{~cm}^{-1}\right)$ & very low \\
\hline trifluoroethanol & $0.52\left(31750 \mathrm{~cm}^{-1}\right)$ & $0.035\left(29410 \mathrm{~cm}^{-1}\right)$ \\
\hline water $(25 \% \mathrm{EtOH})$ & $0.64\left(31750 \mathrm{~cm}^{-1}\right)$ & very low \\
\hline \multicolumn{3}{|c|}{ acid media } \\
\hline \multirow[t]{2}{*}{ acetonitrile } & $0.54\left(32260 \mathrm{~cm}^{-1}\right)$ & $0.17\left(30770 \mathrm{~cm}^{-1}\right)$ \\
\hline & $0.64\left(28170 \mathrm{~cm}^{-1}\right)$ & $0.18\left(29410 \mathrm{~cm}^{-1}\right)$ \\
\hline \multirow[t]{2}{*}{ ethanol } & $0.66\left(32260 \mathrm{~cm}^{-1}\right)$ & very low \\
\hline & $0.71\left(28170 \mathrm{~cm}^{-1}\right)$ & \\
\hline \multirow[t]{2}{*}{ trifluoroethanol } & $0.55\left(32260 \mathrm{~cm}^{-1}\right)$ & $0.15\left(30770 \mathrm{~cm}^{-1}\right)$ \\
\hline & $0.56\left(29410 \mathrm{~cm}^{-1}\right)$ & $0.16\left(29410 \mathrm{~cm}^{-1}\right)$ \\
\hline \multirow[t]{3}{*}{ water $(25 \% \mathrm{EtOH})$} & $0.20\left(32260 \mathrm{~cm}^{-1}\right)$ & very low \\
\hline & $0.20\left(29410 \mathrm{~cm}^{-1}\right)$ & \\
\hline & basic media & \\
\hline water $(25 \% \mathrm{EtOH})$ & - & very low \\
\hline
\end{tabular}

solvents. In addition, a new red-shifted emission band was observed with maximum at $23500 \mathrm{~cm}^{-1}$ and similar intensity to the normal Stokes-shifted band. The fluorescence quantum 15 yield of 1-OMe in trifluoroethanol had a similar value to those observed in other solvents (Table 1). The fluorescence decay of 1-OMe in trifluoroethanol was found to be triexponential at both emission bands (Table 2).

No emission could be detected for 1-NMe in neutral 20 solvents, except for trifluoroethanol, where a very weak fluorescence was detected with emission maximum at 23260 $\mathrm{cm}^{-1}$ (Table 1). The fluorescence spectrum of 1-NMe in trifluoroethanol overlapped the absorption spectrum and did not depend on the monitoring wavelength.

\section{3.3 Fluorescence spectra and lifetimes in acid media}

The fluorescence spectra of 1-OMe in acidified acetonitrile and water with $25 \%$ ethanol exhibited similar features (panels (a) and (b) of Fig. 4). In both solvents, the fluorescence emission and excitation spectra were dependent of the

30 monitoring wavenumber. When monitored at the blue-side of the emission spectrum, the excitation spectrum showed a twoband structure and was blue-shifted compared to the absorption spectrum recorded in the same conditions. In contrast, when monitored at the red side, the excitation 35 spectrum was more similar to the first absorption band. The maximum of the emission band slightly shifted to the red as the excitation wavenumber decreased (for example, in acetonitrile from $23260 \mathrm{~cm}^{-1}$ with excitation at $32260 \mathrm{~cm}^{-1}$ to $22990 \mathrm{~cm}^{-1}$ with excitation at $28170 \mathrm{~cm}^{-1}$ ). The fluorescence 40 spectra of 1-OMe in acidified trifluoroethanol and ethanol exhibited very similar features to those observed in acetonitrile and water with $25 \%$ ethanol.

The fluorescence quantum yield of 1-OMe in acidified acetonitrile and ethanol varied with the excitation 45 wavenumber, showing higher values when the excitation wavenumber decreased. On the contrary, the quantum yield was almost independent of the excitation wavenumber for 1-OMe in trifluoroethanol and water with $25 \%$ ethanol (Table 1). The fluorescence decays of 1-OMe in acidified media 50 were biexponential in all the solvents studied. The relative contributions of the two lifetimes changed systematically with the emission wavenumber (Table 2).

The fluorescence of 1-NMe in acidified media depended strongly on the nature of the solvent. No fluorescence 55 emission could be detected in ethanol and water with $25 \%$ ethanol. On the contrary, a moderately intense fluorescence was observed in acidified acetonitrile and trifluoroethanol (see the quantum yields in Table 1). The absorption and fluorescence spectra of 1-NMe in these solvents are presented 60 in parts (c) and (d) of Fig. 4. The fluorescence spectra were similar in both solvents, showing a single emission band independent of the excitation wavenumber with maximum at $\sim 22700 \mathrm{~cm}^{-1}$. The excitation spectrum was independent of the monitoring wavenumber and its maximum coincided with that ${ }_{65}$ of the absorption spectrum. Nevertheless, in neither solvent did the shape of the excitation spectra match the shape of the absorption spectra, which were in turn very similar in all the solvents investigated. 
Table 2 Fluorescence decay times $\tau$ of compounds 1-OMe and 1-NMe in various solvents at $298 \mathrm{~K}$, obtained by global analysis of the decays at the indicated emission wavenumbers. When a multi-exponential decay function was fitted, it is indicated at each wavenumber the pre-exponential factor B and the associated percentage (in parentheses) of each exponential term. Shown in square brackets are the species to which each lifetime was assigned. The excitation wavenumber was $32470 \mathrm{~cm}^{-1}$ for 1-OMe and $26670 \mathrm{~cm}^{-1}$ for $\mathbf{1 - N M e}$.

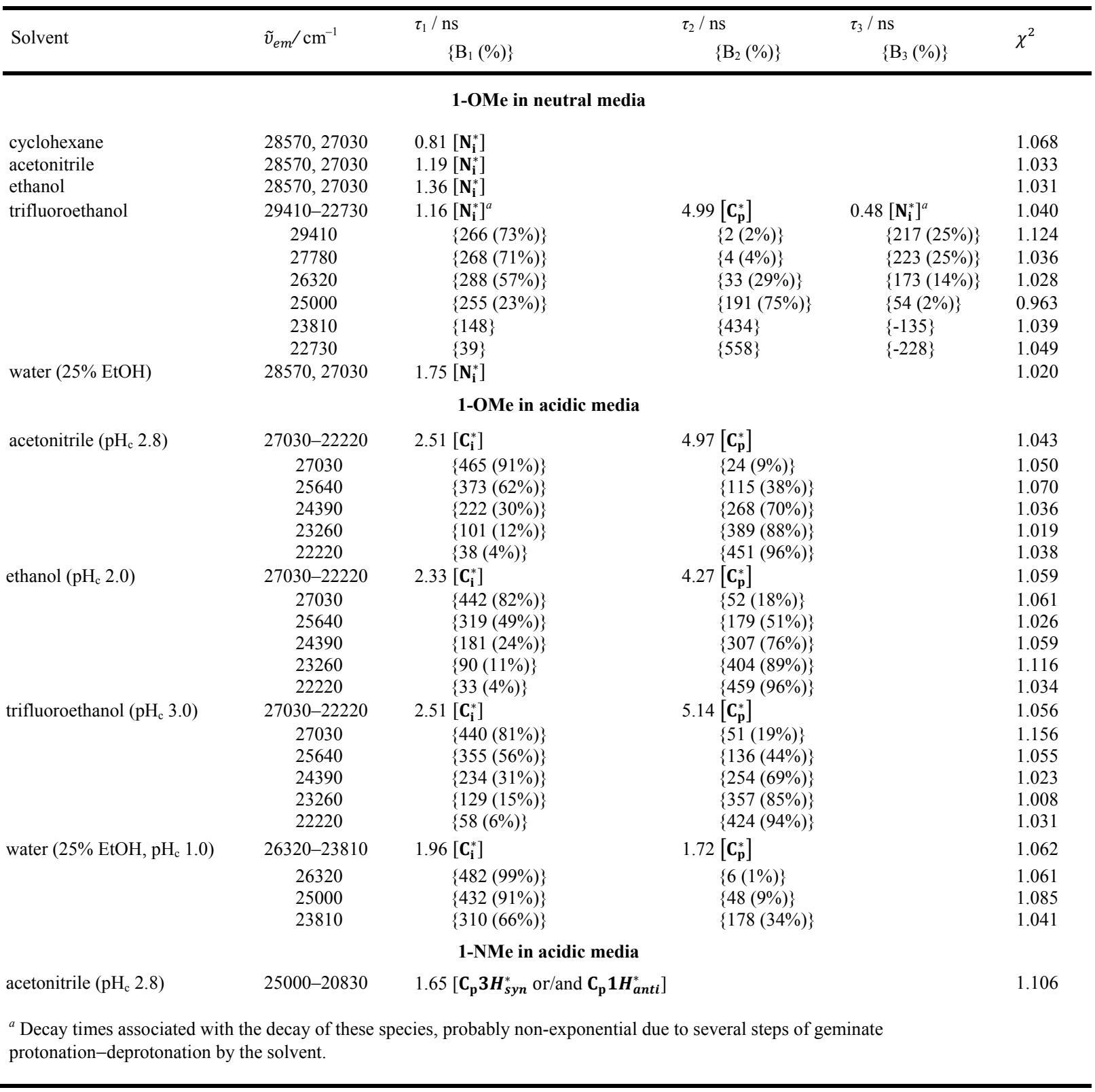

\section{Discussion}

4.1 Acid-base equilibria of 1-NMe and 1-OMe, and groundstate tautomeric equilibria for cationic 1-OMe

10 The absorption spectra of 1-NMe shown in Fig. 2 (b) reveal that this species experiences an acid-base equilibrium in neutral-to-acid solutions, which must be assigned to the protonation of one of the imidazole-type nitrogens. The observed spectral changes are very small, as was also 15 previously found for protonation of many benzimidazole derivatives. ${ }^{63-65}$ In strongly basic media, an additional ground- state equilibrium was found (results not shown), which must correspond to the deprotonation of the $\mathrm{OH}$ group, the only acidic position of the molecule. The series of absorption 20 spectra was analyzed by principal-component global analysis ${ }^{66}$ to obtain the spectral components associated with the protonated (p), neutral (n) and deprotonated (d) forms of 1-NMe, together with their experimental and calculated acidity-dependent spectral contributions $c_{\mathrm{p}}, c_{\mathrm{n}}$, and $c_{\mathrm{d}}$ (cf. 25 inset in part (b) of Fig. 2), and the acidity constants calculated on a concentration basis. The $\mathrm{p} K_{\mathrm{a}}$ value obtained for deprotonation in water was 12.92 . The $\mathrm{p} K_{\mathrm{a}}$ corresponding to the equilibrium between the protonated and the neutral form 


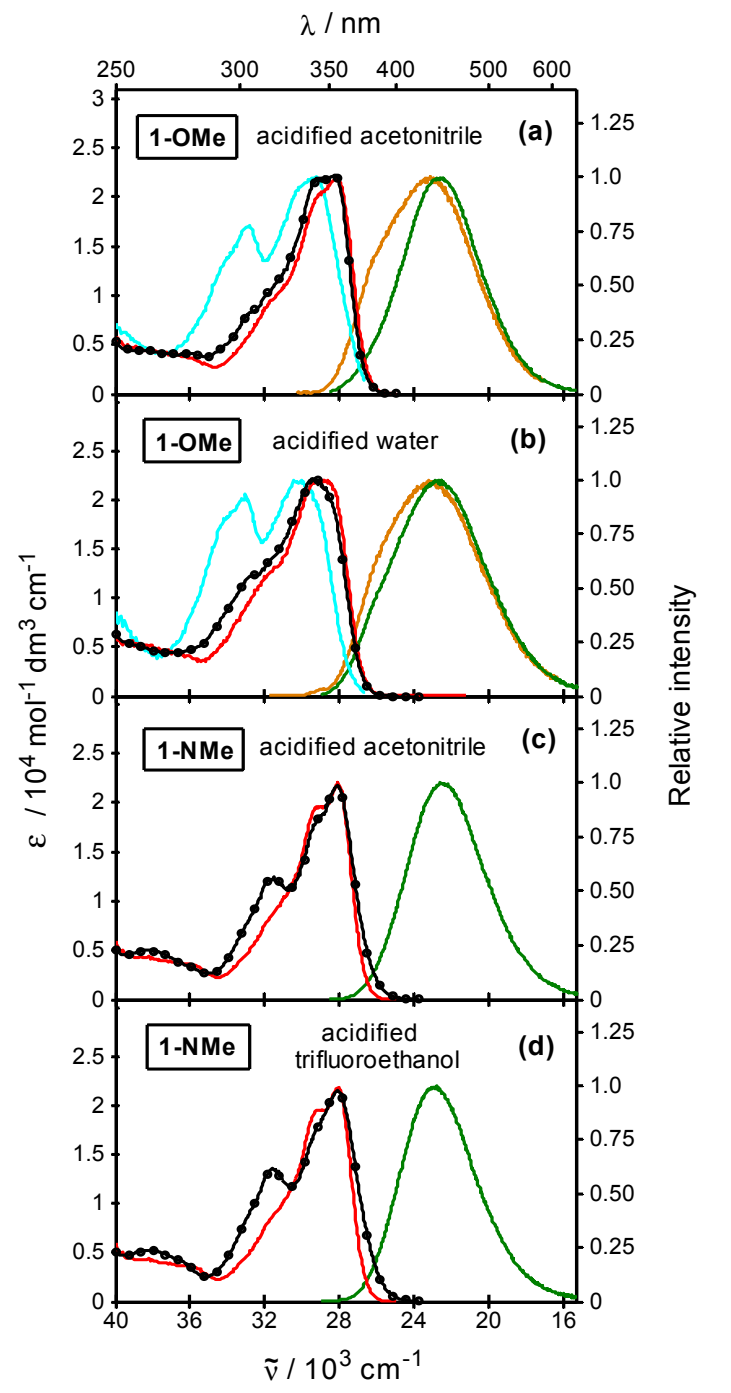

Fig. 4 Absorption spectra (- $(-)$ and normalized fluorescence emission and excitation spectra of (a) 1-OMe in acidified acetonitrile, $[\mathrm{HClO} 4]=1 \times 10^{-3} \mathrm{~mol} \mathrm{dm}^{-3}, \tilde{v}_{e x c}=28990 \mathrm{~cm}^{-1}(-), \tilde{v}_{e x c}=33330$ $\mathrm{cm}^{-1}(-), \tilde{v}_{e m}=26320 \mathrm{~cm}^{-1}(-), \tilde{v}_{e m}=20830 \mathrm{~cm}^{-1}(-)$, (b) 1-OMe 5 in acidified water $\left(25 \%\right.$ ethanol) of $\mathrm{pH}_{\mathrm{c}} 1.0, \tilde{v}_{\text {exc }}=28570 \mathrm{~cm}^{-1}(-)$, $\tilde{v}_{e x c}=33330 \mathrm{~cm}^{-1}(-), \tilde{v}_{e m}=26320 \mathrm{~cm}^{-1}(-), \tilde{v}_{e m}=20830 \mathrm{~cm}^{-1}$ (一), (c) 1-NMe in acidified acetonitrile, [HClO4] $=1 \times 10^{-3} \mathrm{~mol}$ $\mathrm{dm}^{-3}, \tilde{v}_{\text {exc }}=29420 \mathrm{~cm}^{-1}(-), \tilde{v}_{e m}=22730 \mathrm{~cm}^{-1}(-)$ and (d) 1-NMe in acidified trifluoroethanol, [HClO4] $=1 \times 10^{-3} \mathrm{~mol} \mathrm{dm}^{-3}, \tilde{v}_{\text {exc }}=$ $1029420 \mathrm{~cm}^{-1}(-), \tilde{v}_{e m}=22730 \mathrm{~cm}^{-1}(-)$.

was 5.31 (Table 3).

The absorption spectra of 1-OMe in ethanol at different acidities are shown in Fig. 2 (a). A ground-state equilibrium 15 was found within the $\mathrm{pH}$ range $3-7$. By applying principal component global analysis to the series of absorption spectra of 1-OMe, we obtained the spectral components associated with the protonated (p) and neutral (n) forms, together with their experimental and calculated acidity-dependent spectral 20 contributions $c_{\mathrm{p}}$ and $c_{\mathrm{n}}$, (see inset in part (a) of Fig. 2), and the acidity constant $\mathrm{p} K_{\mathrm{a}}$ shown in Table 3 . The $\mathrm{p} K_{\mathrm{a}}$ value obtained in the same way for 1-OMe in water with $25 \%$ of ethanol
Table 3 Experimental values for the macroscopic acidity constants $\left(\mathrm{p} K_{\mathrm{a}}\right)$ of protonated 1-OMe and 1-NMe in various solvents at $298 \mathrm{~K}$, 25 and estimated values of the equilibrium constant between imidazolium and pyridinium cations of 1-OMe $\left(K_{\mathrm{ip}}\right)$ and microscopic acidity constants of each cation in the ground state $\left(\mathrm{p} K_{\mathrm{a}(\mathrm{i})}\right.$ and $\left.\mathrm{p} K_{\mathrm{a}(\mathrm{p})}\right)$ and the first-excited singlet state $\left(\mathrm{p} K_{\mathrm{a}(\mathrm{i})}^{*}\right.$ and $\left.\mathrm{p} K_{\mathrm{a}(\mathrm{p})}^{*}\right)$. Last columns list the hydrogen-bond donor $(\alpha)$ and hydrogen-bond acceptor $(\beta)$ ability 30 of the pure solvents. ${ }^{67}$

Solvent

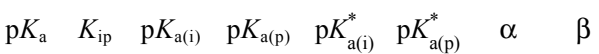

\begin{tabular}{|c|c|c|c|c|c|c|c|c|}
\hline \multicolumn{9}{|c|}{ 1-OMe } \\
\hline Acetonitrile & & 8.8 & & & & & 0.19 & 0.31 \\
\hline Ethanol & 5.40 & 5.6 & 4.6 & 5.3 & $8^{a}$ & $12^{a}$ & 0.83 & 0.77 \\
\hline $\begin{array}{l}\text { Water } \\
(25 \% \mathrm{EtOH})\end{array}$ & 4.00 & 3.9 & 3.3 & 3.9 & $7^{a}$ & $10^{a}$ & 1.17 & 0.18 \\
\hline Trifluoroethanol & & 3.7 & & & & & 1.51 & 0 \\
\hline
\end{tabular}

Water

$(25 \% \mathrm{EtOH})$

${ }^{a}$ Values calculated by using the Förster cycle method.

(4.00) is very similar to that reported by Dogra et al (4.1). ${ }^{59}$

1-OMe possesses two basic groups, the imidazole nitrogen 35 and the pyridine nitrogen. As we stated before, protonation at the benzimidazole nitrogen hardly changes the absorption spectrum. ${ }^{63-65}$ This was experimentally verified for 1-NMe, as there is no significant shift between the spectrum of the neutral and protonated forms (cf. Fig. 2 (b)). Conversely, 40 protonation at the pyridine or quinoline nitrogen in pyridylbenzimidazoles, ${ }^{63,64,68}$ or quinoline derivatives ${ }^{69,} 70$ produces generally a red shift of the absorption spectrum. As can be seen in Fig. 2 (a), the absorption spectrum of 1-OMe in acid media is considerably red shifted with respect to the 45 neutral form spectrum, indicating that protonation probably takes place to a great extent at the pyridine nitrogen. Moreover, the fluorescence spectra and lifetimes of 1-OMe in acid media (to be discussed in the next section, $c f$. Fig. 4 (a) and (b) and Table 2) have led us to propose that two different 50 monocations exist for 1-OMe at equilibrium in the ground state. Scheme 1 presents the ground-state equilibria proposed for 1-OMe in acid media. We designate the two protonated species as imidazolium cation $\left(\mathbf{C}_{\mathbf{i}}\right)$ and pyridinium cation $\left(\mathbf{C}_{\mathbf{p}}\right)$, and the corresponding microscopic acidity constants for s5 each cation as $K_{\mathrm{a}(\mathrm{i})}$ and $K_{\mathrm{a}(\mathrm{p})}$. The neutral species is represented by the $1 H$ tautomer with an intramolecular hydrogen bond, which is probably the most stable structure in polar solutions according to NMR results on related species ${ }^{60}$ and quantum mechanical calculations, ${ }^{59}$ but a considerable 60 amount must also exist of the $3 H$ tautomer, as was demonstrated in this work for 1-OMe in dimethyl sulfoxide (see the experimental section) and for related species ${ }^{60}$ in the same solvent. The cations $\mathbf{C}_{\mathbf{i}}$ and $\mathbf{C}_{\mathbf{p}}$ probably experience also a rotational isomerism, but the UV-Vis spectral properties of 


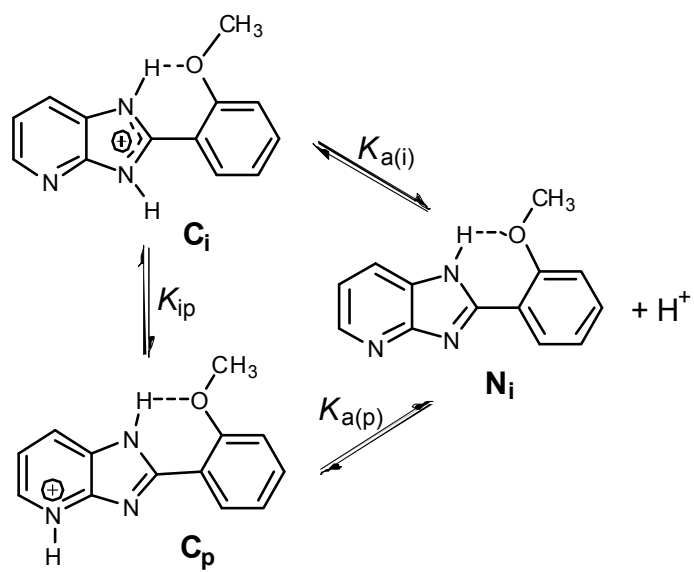

Scheme 1 Acid-base equilibria between neutral and cationic forms of 1-OMe.

both rotamers, as those of the corresponding $1 H-3 H$ 5 tautomers of $\mathbf{N}_{\mathbf{i}}$, must be very similar.

The formation of the pyridinium cation is supported by the comparison of the spectra of 1-OMe and 1-NMe in acid media (Fig. 2), which show the first-band absorption in the same region. As the pyridinium cation $\mathbf{C}_{\mathbf{p}}$ of 1-OMe must have a 10 very similar electronic structure to the protonated form of 1-NMe (only hydrogen atoms replacing the methyl groups of each species), the similarity of the absorption spectra for 1-OMe and 1-NMe in acid media supports the assumption that 1-OMe protonates to a great extent at the pyridinium 15 nitrogen.

The measured macroscopic acidity constant $K_{\mathrm{a}}$ is related to the microscopic constants $K_{\mathrm{a}(\mathrm{i})}$ and $K_{\mathrm{a}(\mathrm{p})}$ by the equation:

$\frac{1}{K_{\mathrm{a}}}=\frac{1}{K_{\mathrm{a}(\mathrm{i})}}+\frac{1}{K_{\mathrm{a}(\mathrm{p})}}$

Defining the equilibrium constant between the cations, $K_{\text {ip }}$, 20 as the ratio between the concentrations of pyridinium and imidazolium cations, the following relation holds between $K_{\text {ip }}$ and the microscopic acidity constants $K_{\mathrm{a}(\mathrm{i})}$ and $K_{\mathrm{a}(\mathrm{p})}$ (see Scheme 1):

$K_{\mathrm{ip}}=\frac{\left[\mathrm{C}_{\mathrm{p}}\right]}{\left[\mathbf{C}_{\mathrm{i}}\right]}=\frac{K_{\mathrm{a}(\mathrm{i})}}{K_{\mathrm{a}(\mathrm{p})}}$

25 The microscopic constants $K_{\mathrm{a}(\mathrm{i})}$ and $K_{\mathrm{a}(\mathrm{p})}$ cannot be obtained spectrophotometrically, since the absorption spectra of the imidazolium and pyridinium cations cannot be recorded separately. As the macroscopic acidic constant $K_{\mathrm{a}}$ is experimentally measured, it is necessary to know one of the 30 microscopic constants, $K_{\mathrm{a}(\mathrm{i})}, K_{\mathrm{a}(\mathrm{p})}$ or $K_{\mathrm{ip}}$, to calculate the other two by equations 1 and 2 . We estimated $K_{\text {ip }}$ by fluorescence measurements, as will be described in the next section.

4.2 Interpretation of the absorption, fluorescence spectra and lifetimes of 1-OMe in acidic solutions: resolution of the 35 strongly overlapping absorption and fluorescence spectra from pyridinium and imidazolium cations

Both the fluorescence excitation and emission spectra of 1-OMe in acidic media depended on the monitoring wavenumber ( $c f$. panels (a) and (b) of Fig. 4), indicating that 40 there is more than one species present in both the ground and the excited states. This finding supports the hypothesis presented in last section that ground-state pyridinium and imidazolium cations coexist in equilibrium. The fluorescence emission spectra showed considerable overlap with the 45 excitation spectra, suggesting that the excited and the emitting species are the same, i.e. the pyridinium and imidazolium cations. The biexponential fluorescence decays with positive amplitudes obtained for 1-OMe in acidified acetonitrile, ethanol, trifluoroethanol and water with $25 \%$ ethanol (Table ${ }_{50} 2$ ) support the proposal that two independent emitting species exist in solution.

We mentioned above that the first absorption band of the pyridinium cation must be significantly red shifted with respect to that of the imidazolium cation. Therefore, the red55 shifted excitation spectrum, which was obtained by monitoring at the red tail of the emission spectrum of 1-OMe in acid media ( $c f$. parts (a) and (b) of Fig. 4), must have a larger contribution from the pyridinium cation $\mathbf{C}_{\mathbf{p}}$ spectrum; conversely, the blue-shifted excitation spectrum, monitored at 60 the higher-energy end of the emission spectrum, must include a major contribution from the imidazolium cation $\mathbf{C}_{\mathbf{i}}$. The higher fluorescence quantum yield values obtained by exciting protonated 1-OMe in acetonitrile or ethanol at the red end of the absorption spectrum (Table 1) indicate therefore that the ${ }_{65}$ pyridinium cation has a higher fluorescence quantum yield than the imidazolium cation in these solvents.

To throw light on the ground-state equilibrium between pyridinium and imidazolium cations, series of fluorescence excitation spectra were recorded for 1-OMe in several 70 acidified solvents at different emission wavelengths, from 360 $\mathrm{nm}$ to $490 \mathrm{~nm}$ in steps of $5 \mathrm{~nm}$ (a total of 27 excitation spectra for each solvent). Assuming that the fluorescent species in sufficiently acidified media are indeed $\mathbf{C}_{\mathbf{i}}^{*}$ and $\mathbf{C}_{\mathbf{p}}^{*}$, any excitation spectra $\mathbf{E}$ should be the sum of contributions from ${ }_{75} \mathbf{C}_{\mathbf{i}}^{*}$ and $\mathbf{C}_{\mathbf{p}}^{*}$ excitation spectra $\left(\mathbf{E}_{\mathrm{C}_{\mathrm{i}}}\right.$ and $\mathbf{E}_{\mathrm{C}_{\mathrm{p}}}$ respectively, see equation 3 ).

$\mathbf{E}=c_{\mathrm{C}_{\mathrm{i}}} \mathbf{E}_{\mathrm{C}_{\mathrm{i}}}+c_{\mathrm{C}_{\mathrm{p}}} \mathbf{E}_{\mathrm{C}_{\mathrm{p}}}$

In this equation, the coefficients $c_{\mathrm{C}_{\mathrm{i}}}$ and $c_{\mathrm{C}_{\mathrm{p}}}$ represent the relative contributions from $\mathbf{C}_{\mathbf{i}}^{*}$ and $\mathbf{C}_{\mathbf{p}}^{*}$ spectra to any 80 experimental excitation spectrum at the corresponding emission wavelength. A principal component analysis of the experimental series indicated that two independent spectral components are needed to reproduce the fluorescence excitation spectra of 1-OMe in different acidified media, ${ }_{85}$ confirming the proposal of eqn (3). The coefficients $c_{\mathrm{C}_{\mathrm{i}}}$ and $c_{\mathrm{C}_{\mathrm{p}}}$ are proportional to the amount of photons emitted by each species at the corresponding emission wavelength, which in turn is modulated by the shape of the fluorescence emission spectra of each species. The unstructured emission spectra 90 shown Fig. 4 (a) and (b) allow us to assume that the fluorescence emission spectra of $\mathbf{C}_{\mathbf{i}}^{*}$ and $\mathbf{C}_{\mathbf{p}}^{*}$ will properly fit to log-normal functions. ${ }^{71}$ Therefore, a principal component global analysis ${ }^{66}$ was performed on the fluorescence excitation spectral series, assuming that the wavenumber dependence of ${ }_{95}$ the coefficients $c_{\mathrm{C}_{\mathrm{i}}}$ and $c_{\mathrm{C}_{\mathrm{p}}}$ follows a log-normal distribution. In the fitting process, the component excitation spectra $\mathbf{E}_{\mathrm{C}_{\mathrm{i}}}$ and $\mathbf{E}_{\mathrm{C}_{\mathrm{p}}}$ are obtained, as well as their experimental and calculated contributions $c_{\mathrm{C}_{\mathrm{i}}}$ and $c_{\mathrm{C}_{\mathrm{p}}}$ (see Fig. 5). The experimental excitation spectra of 1-OMe at any emission 


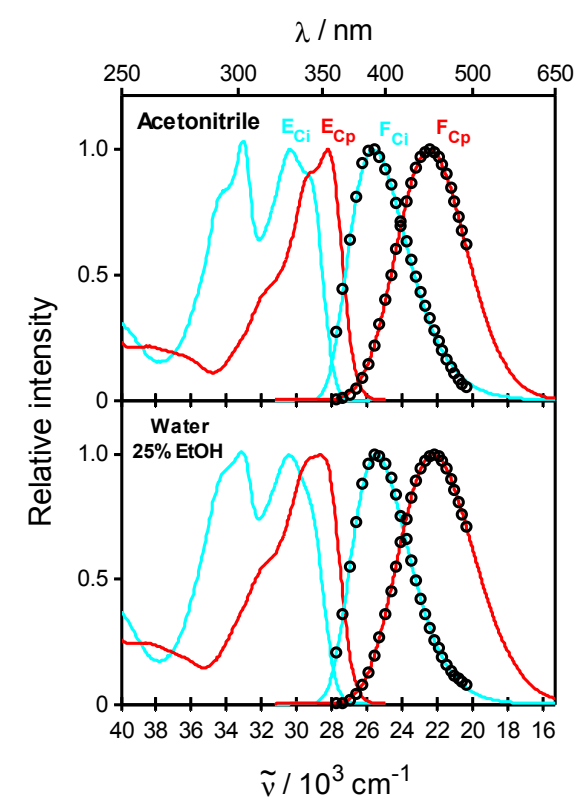

Fig. 5 Normalized fluorescence excitation $\left(\mathbf{E}_{\mathrm{C}_{\mathrm{i}}}\right.$ and $\left.\mathbf{E}_{\mathrm{C}_{\mathrm{p}}}\right)$ and emission $\left(\mathbf{F}_{\mathrm{C}_{\mathrm{i}}}\right.$ and $\left.\mathbf{F}_{\mathrm{C}_{\mathrm{p}}}\right)$ spectra of the imidazolium (-) and pyridinium (-) cations of 1-OMe in acidified acetonitrile and water ( $25 \%$ ethanol). The excitation spectra were obtained as component 5 spectra in a principal component global analysis of a series of 27 excitation spectra at different emission wavenumbers. The analysis also yielded the wavenumber-dependent coefficients (o) of the component spectra. The fitting of a log-normal function to these coefficients provided the emission spectra.

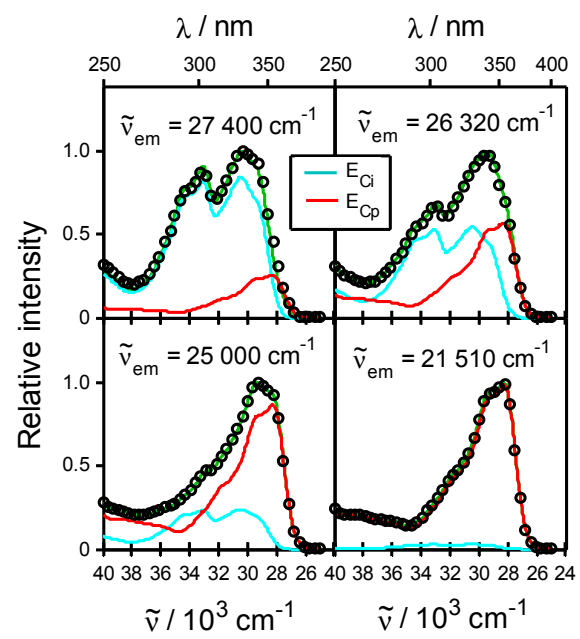

Fig. 6 Normalized experimental (-) and calculated (o) fluorescence excitation spectra of 1-OMe in acidified ethanol at different emission wavenumbers. The calculated spectra were obtained as linear combination of the component excitation spectra associated to the 15 imidazolium (-) and pyridinium (-) cations, whose individual contributions are also shown. Principal component global analysis of a series of 27 excitation spectra provided the imidazolium and pyridinium cations component spectra.

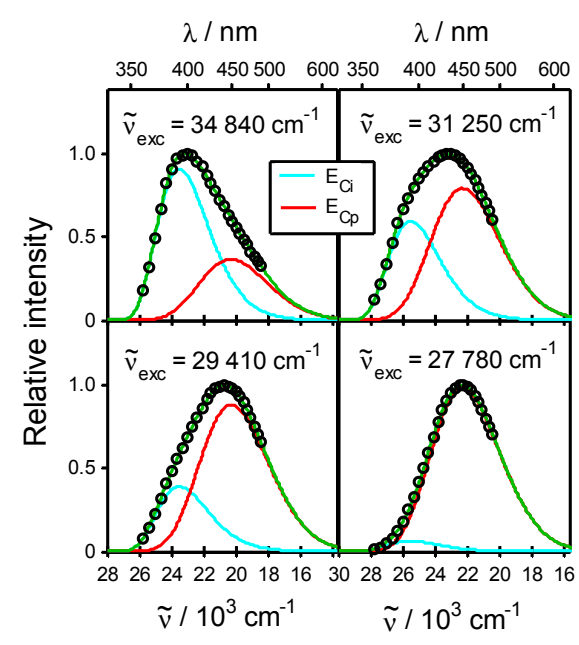

Fig. 7 Normalized experimental (o) and calculated (-) fluorescence emission spectra of 1-OMe in acidified water with $25 \%$ ethanol at different excitation wavenumbers. The calculated spectra were obtained by fitting a linear combination of the imidazolium (-) and 25 pyridinium (-) cation emission spectra obtained by principal component global analysis as described in Section 4.2 and Fig. 5.

wavelength are well fitted by this model (see in Fig. 6 the results for ethanol; similar results were obtained for the rest of 30 the solvents). The excitation spectra $\mathbf{E}_{\mathrm{C}_{\mathrm{i}}}$ and $\mathbf{E}_{\mathrm{C}_{\mathrm{p}}}$ obtained in the analysis differ markedly in shape and position of the band maxima and bear, as expected, some resemblance to the experimental excitation spectra obtained at the red and blue side of the 1-OMe emission spectrum (Fig. 4).

35 The fitting and extrapolation of a log-normal function to the coefficients $c_{\mathrm{C}_{\mathrm{i}}}$ and $c_{\mathrm{C}_{\mathrm{p}}}$ obtained from the principal component global analysis yielded the individual fluorescence emission spectra of each cation, $\mathbf{F}_{\mathrm{C}_{\mathrm{i}}}$ and $\mathbf{F}_{\mathrm{C}_{\mathrm{p}}}$. Fig. 5 shows the results obtained in acidified acetonitrile and water with $25 \%$ 40 ethanol. The experimental fluorescence emission spectra of 1-OMe in acidified solvents could be satisfactorily reproduced by a linear combination of $\mathbf{F}_{\mathrm{C}_{\mathrm{i}}}$ and $\mathbf{F}_{\mathrm{C}_{\mathrm{p}}}$. The good quality of the fit for acidified water with $25 \%$ ethanol can be seen in Fig. 7 at several excitation wavenumbers.

45 Once the excitation spectra of $\mathbf{C}_{\mathbf{i}}^{*}$ and $\mathbf{C}_{\mathbf{p}}^{*}$ were known, we tried to reproduce the experimental absorption spectrum of 1-OMe in acidified media as a linear combination of $\mathbf{E}_{\mathrm{C}_{\mathrm{i}}}$ and $\mathbf{E}_{\mathrm{C}_{\mathrm{p}}}$. The results are shown in Fig. 8, where the contribution from each cation to the absorption spectrum of 1-OMe in 50 various acidified solvents and the goodness of the fits can be appreciated. An excellent agreement is found between the spectra calculated by the method described and the experimental absorption spectra, which confers additional support to the analysis performed.

55 Fig. 8 shows graphically that the contribution from the pyridinium cation to the first absorption band of 1-OMe is greater than that of the imidazolium cation in all the solvents studied, the latter having a maximum contribution in trifluoroethanol and minimum in acetonitrile. The ${ }_{60}$ determination of the equilibrium constant between the cations from the spectral contributions shown in Fig. 8 requires knowing the molar absorption coefficient of one cation at 


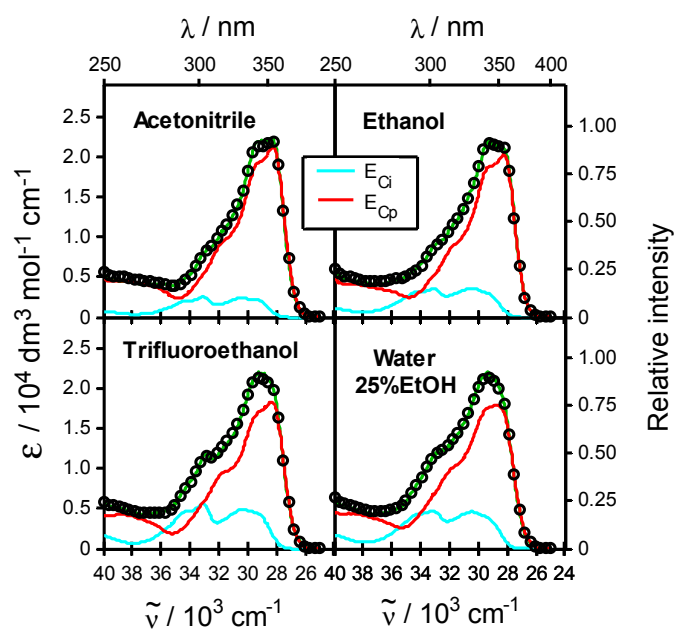

Fig. 8 Experimental (-) and calculated (o) absorption spectra of 1-OMe in different acidified media. Principal component global analysis of a series of 27 excitation spectra collected at different emission wavenumbers provided the imidazolium (-) and 5 pyridinium (-) cations excitation spectra, whose linear combination was fitted to the experimental absorption spectra.

some wavelength. Our results do not allow obtaining this datum, as both cations are always present in comparable 10 amounts in solution. We can make nevertheless a reasonable guess for the maximum molar absorption coefficients of the cations at the first absorption band $\left(\varepsilon_{\max }\right)$, based on the following data:

(i) for many benzimidazole derivatives, protonation at the 15 benzimidazole nitrogen doesn't change $\varepsilon_{\max } \cdot{ }^{63-65}$ The spectra of 1-NMe proved this assertion (see part (b) of Fig. 2). Based on these facts, we anticipate for the imidazolium cation of 1-OMe a similar $\varepsilon_{\max }$ to the neutral form;

(ii) the chemical structure of the 1-OMe pyridinium cation 20 is very similar to that of the only cation of 1-NMe (only hydrogen atoms replacing methyl groups in each other's structure), so we expect a similar $\varepsilon_{\max }$ for both cations;

(iii) the $\varepsilon_{\max }$ values for 1-OMe and 1-NMe, both in neutral and acidic solutions in different solvents, are very similar (see ${ }_{25}$ Fig. 2).

These facts led us to assume that $\varepsilon_{\max }$ is similar for the imidazolium and pyridinium cations of 1-OMe. Under this approximation, from the ratio of maximum absorbances of the pyridinium and imidazolium cations in the spectral 30 decompositions of Fig. 8, we can estimate the equilibrium constant between the cations $\left(K_{\text {ip }}\right)$ in the solvents studied. The estimated values (Table 3) show that the fraction of pyridinium cation is always much greater than that of the imidazolium cation in the solvents studied here. This result is 35 in keeping with the predominant protonation at the pyridine nitrogen found for the closely related species 2-(2',4'dimethoxyphenyl)imidazo[4,5-b]pyridine by ${ }^{1} \mathrm{H}$ NMR measurements. ${ }^{60}$

The estimated $K_{\text {ip }}$ values for 1-OMe decrease in the order 40 acetonitrile $>$ ethanol $>$ water $>$ trifluoroethanol (Table 3 ). This means that the fraction of pyridinium cation $\mathbf{C}_{\mathbf{p}}$ reaches a maximum in acetonitrile (see Fig. 8). The dipolar solute- solvent interactions do not seem to be the main factor affecting this trend, as the dielectric constant of acetonitrile 45 has an intermediate value between water and the alcohols, and the more polar pyridinium cation should become more stabilized in water than in acetonitrile by dipolar interactions. To test whether the hydrogen-bond interactions are the key factors determining the relative stability of the cations in the ${ }_{50}$ different solvents, we examined the values of the parameters representing the hydrogen-bond donor $(\alpha)$ and the hydrogenbond acceptor $(\beta)$ ability of the solvent, listed in Table $3 .{ }^{67} \mathrm{It}$ is observed that the $K_{\text {ip }}$ values of 1-OMe decrease as $\alpha$ increases, showing in turn no correlation with $\beta$. This means ${ }_{55}$ that the fraction of imidazolium cation reaches a maximum in trifluoroethanol, the solvent with the highest hydrogen-bond donor ability. Since $\mathbf{C}_{\mathbf{i}}$ and $\mathbf{C}_{\mathbf{p}}$ isomers of 1-OMe differ only in the kind of nitrogen available for accepting a hydrogen bond from the solvent (see Scheme 1), we can conclude that 60 the hydrogen-bond donor interaction of the solvent with the pyridine nitrogen must be very strong and the key factor contributing to the relative stabilization of the imidazolium cation in hydrogen-bonding solvents.

The experimental $\mathrm{p} K_{\mathrm{a}}$ values for 1-OMe in ethanol and ${ }_{65}$ water, together with the estimated $K_{\text {ip }}$ values, allow for the determination of the microscopic acidity constants $K_{\mathrm{a}(\mathrm{i})}$ and $K_{\mathrm{a}(\mathrm{p})}$ by using eqns. (1) and (2). The values obtained, listed in Table 3, show that the pyridine nitrogen is slightly more basic than the imidazole nitrogen for 1-OMe. An estimation of the 70 acidity constants in the first-excited singlet state can be obtained by the Förster cycle method. ${ }^{72}$ As the spectra do not show vibrational structure, the energy of the $(0,0)$ band was estimated by the intersection point between the normalized excitation and emission fluorescence spectra of each species. ${ }^{73}$ 75 The $\mathrm{p} K_{\mathrm{a}}^{*}$ values obtained ( $c f$. Table 3 ) indicate that the pyridine nitrogen becomes much more basic in the excited state, showing a strongly photobasic character with an increase in the $\mathrm{pK}_{\mathrm{a}}$ of more than 6 units upon excitation. The imidazole nitrogen is also more basic in the excited state, but ${ }_{80}$ the basicity increase is much smaller than that of the pyridine nitrogen.

Some insight into the electronic properties of the species studied might be obtained by a comparison of the $\mathrm{p} K_{\mathrm{a}}$ values with those of related molecules. The $\mathrm{p} K_{\mathrm{a}(\mathrm{i})}$ value for 1-OMe in 85 water (3.3) is nearly 2 units lower than that for 2-(2'methoxyphenyl)benzimidazole $(5.1),{ }^{74}$ which lacks the pyridine nitrogen of 1-OMe. This result shows that the pyridine nitrogen has a strong electron-withdrawing effect, enhancing the acidity of the imidazolium cation of 1-OMe.

90 The $\mathrm{p} K_{\mathrm{a}}$ value obtained for protonated 1-NMe (5.31) is significantly higher than that corresponding to the pyridinium cation of 1-OMe (3.9). Since the protonated form of 1-NMe has formally the same electronic structure as the pyridinium cation $\mathbf{C}_{\mathbf{p}}$, the lower resonance energy and consequent higher 95 energy content of neutral 1-NMe compared to neutral 1-OMe could explain the weaker acidity of the 1-NMe cation. In the same way, the measured $\mathrm{p} K_{\mathrm{a}}$ value for $\mathrm{OH}$-deprotonation of 1-NMe (12.92) is much higher than the value obtained for the non-methylated parent molecule 2-(2'-hydroxyphenyl)imidazo $100[4,5-b]$ pyridine $(8.6),{ }^{75}$ indicating a lower capacity of $\mathbf{1 - N M e}$ 
anion to stabilize the negative charge through resonance effects and the formation of an intramolecular hydrogen bond $\mathrm{N}-\mathrm{H}^{\cdots} \cdots \mathrm{O}^{-}$.

The fluorescence decay of protonated 1-OMe is 5 biexponential (Table 2). At the red end of the emission spectrum, the longer lifetime shows its maximum relative contribution to the fluorescence decay in acetonitrile, ethanol and trifluoroethanol. This lifetime ( $4-5 \mathrm{~ns}$ ) has therefore to be assigned to the pyridinium cation, and the shorter lifetime $10(2.3-2.5 \mathrm{~ns})$ to the imidazolium cation.

The fluorescence properties of 1-OMe were similar in acidic aqueous solution $(25 \% \mathrm{EtOH})$ and in the rest of the solvents, only a lower quantum yield (Table 1) and shorter lifetimes (Table 2) being noticed as distinctive differences. In 15 contrast to other solvents, the longest fluorescence lifetime in water (1.96 ns) shows its maximum contribution to the decay at the higher-energy side of the emission spectrum (Table 2), indicating that this decay time has to be attributed to the imidazolium cation. The shorter lifetime (1.72 ns), with 20 maximum contribution at lower wavenumbers, has to be assigned to the pyridinium cation. Comparison of these lifetimes with those found in other solvents (Table 2) shows that the excited-state lifetime of the imidazolium cation is only a bit shorter in aqueous solution than in other solvents, 25 but the pyridinium lifetime is much shorter in aqueous solution. As the spectra are similar in all the solvents, these results suggest that the radiationless deactivation of the pyridinium cation is much faster in aqueous solution than in other solvents. This fact is probably the main reason for the

30 lower fluorescence quantum yield of protonated 1-OMe in water relative to other solvents (Table 1).

4.3 Excited-state behaviour of 1-OMe in neutral solutions: photobasic properties of the pyridine nitrogen

The fluorescence properties of 1-OMe were very similar for 35 all the solvents studied except trifluoroethanol, which will be discussed later. The following experimental results are important for the discussion: (a) similar fluorescence excitation and emission spectra with small Stokes shift were obtained for 1-OMe in all the solvents examined (Fig. 3); (b)

40 the excitation and emission spectra were independent of the monitoring wavenumber; (c) the excitation spectrum perfectly matched the absorption spectrum; (d) a monoexponential fluorescence decay was observed in all the solvents (Table 2).

The fluorescence behaviour of 1-OMe just described 45 suggests that only one absorbing and emitting species exists in the solvents mentioned. The well-resolved vibronic structure and mirror-image relationship of the absorption and fluorescence spectra suggests that this species has a planar configuration in both the ground and the excited states, since

50 loss of planarity in this kind of molecules gives rise to a large hypsochromic shift and loss of vibrational structure. ${ }^{76-79}$ In Fig 1, we represent neutral 1-OMe by the $\mathbf{N}_{\mathbf{i}}$ structure, but we don't know the main conformation of this species in solution, as the benzimidazole hydrogen could be attached to the $\mathrm{N}(1)$ 55 or N(3) position, and the methoxyphenyl group could be rotated. The fluorescence measurements seem to indicate that one of these conformations is in much greater concentration than the others, but our results do not allow finding out which one is the main conformation.

60 The absorption and fluorescence spectra of neutral 1-OMe in acetonitrile, ethanol and water were very alike (see Fig. 3), this fact indicating a constant value of the radiative deactivation constant in these solvents. Nevertheless, both the fluorescence quantum yields and lifetimes increase in the 65 series acetonitrile $<$ ethanol $<$ water $(25 \% \mathrm{EtOH})$, the increase in the lifetime value being larger than in the quantum yield value. These facts imply that a decrease in the radiationless deactivation constant takes place in the series acetonitrile > ethanol $>$ water $(25 \% \mathrm{EtOH})$, as has already been found in a 70 previous investigation. ${ }^{59}$ The data obtained suggest that the hydrogen-bond interactions with the solvent molecules induce this decrease in the radiationless deactivation rate constant.

1-OMe showed dual fluorescence in trifluoroethanol (panel (c) of Fig. 3). In addition to the normal Stokes-shifted band 75 also observed in other solvents, a new large Stokes-shifted emission appeared with almost the same intensity. The excitation spectra obtained at both emission bands were identical, matching perfectly the absorption spectrum of 1-OMe. This finding shows that both emission bands derive 80 from the same ground-state precursor. The great similarity of the absorption spectra in all the solvents examined ( $c f$. Fig. 3) strongly supports that this precursor must be the neutral form of 1-OMe, no absorption by different species being detected.

Investigations on several pyridyl derivatives of 85 benzimidazole and related molecules have shown that the pyridine nitrogen strongly increases its basicity on excitation, becoming protonated even by water in neutral medium. ${ }^{63,68,80}$, ${ }^{81}$ No such behaviour was observed for the benzimidazole nitrogens, which do not show detectable photobasic ${ }_{90}$ properties. ${ }^{68}$ Based on these facts, we expected for 1-OMe a strongly increased basicity of the pyridine nitrogen in the excited state. The excited-state acidity constants estimated by the Förster cycle method (Table 3 ) confirm this hypothesis, as they predict more than 6 units increase in the $\mathrm{p} K_{\mathrm{a}(\mathrm{p})}$ of the 95 pyridinium cation upon excitation, but only 3-4 units increase for the $\mathrm{p} K_{\mathrm{a}(\mathrm{i})}$ of the imidazolium cation of 1-OMe. This means that an acidic solvent like trifluoroethanol $\left(\mathrm{pK}_{\mathrm{a}} 12.37\right),{ }^{82}$ will probably be able to protonate the pyridine nitrogen of 1-OMe in the excited state. According to this hypothesis, the red100 shifted band and the long fluorescence lifetime showing maximum amplitude at lower wavenumbers (4.99 ns, Table 2) have to be assigned to the emission of the pyridinium cation $\mathbf{C}_{\mathbf{p}}^{*}$ of 1-OMe, formed by protonation in the excited state of the neutral molecule. This assignment is supported by the 105 measurements carried out in acidified trifluoroethanol (see above), which showed an emission with similar features and lifetime (5.14 ns, Table 2), assigned to the pyridinium cation.

Scheme 2 summarizes the proposed excitation and deactivation pattern for 1-OMe in trifluoroethanol solution. 110 The excited non-protonated molecules of 1-OMe would emit the normal Stokes-shifted emission band $\left(\sim 28400 \mathrm{~cm}^{-1}\right)$, very similar to the fluorescence measured in non-acidic solvents like acetonitrile or ethanol ( $c f$. Fig. 3). The fluorescence decay of this band was found to be triexponential in trifluoroethanol 115 (Table 2). The longest decay (4.99 ns), with very low 


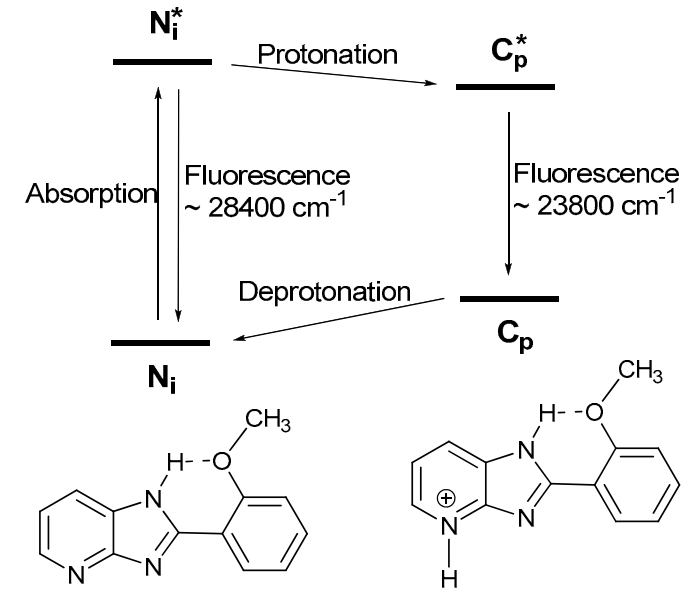

Scheme 2 Excitation and deactivation pattern proposed for 1-OMe in neutral trifluoroethanol solution.

contribution, must correspond to the red-shifted pyridinium 5 band tail, but the two shorter lifetimes ( $1.16 \mathrm{~ns}$ and $0.48 \mathrm{~ns}$ ), with maximum contribution on the blue side of the emission spectrum, have to be associated with the decay of the excited neutral species. The pre-exponential factors of these lifetimes are positive at wavelengths corresponding to the normal 10 Stokes-shifted band, decreasing with wavenumber and reaching negative values for the shorter lifetime at the lowest wavenumbers. This is an indication that the pyridinium cation emitting at low wavenumbers is formed in the excited state from species emitting at the normal Stokes-shifted band.

15 Nevertheless, a simple scheme of one-step protonation of the neutral molecule by the solvent would not explain the triexponential fluorescence decay. The coexistence in the excited state of both the neutral and the protonated pyridinium forms of 1-OMe in trifluoroethanol means that probably the 20 protonation process is reversible, due to similar basicities of solute and conjugate base of the solvent. In this case, several steps of geminate protonation-deprotonation of excited 1-OMe by the solvent would probably take place, as it has been thoroughly studied for the analogous processes of ${ }_{25}$ photoacid deprotonation by the solvent. ${ }^{83,84}$ This scheme leads to time-dependent rate constants and non-exponential decays. If the same behaviour holds for photoprotonation of the neutral form of 1-OMe, the triexponential fit would give only an approximation to the real decay.

30 The fact that the fluorescence quantum yields of 1-OMe show comparable values in trifluoroethanol and the rest of the solvents studied (Table 1) indicates that the neutral form of 1-OMe and its pyridinium cation have similar quantum yields. Consequently, the similar intensities of the fluorescence bands 35 associated with these species imply that both are present in comparable amounts in the excited state in trifluoroethanol.

4.4 Excited-state behaviour of 1-NMe in neutral solutions: proton-coupled charge-transfer hypothesis (ESIPT-TICT mechanism)

40 1-NMe in neutral media showed no detectable fluorescence emission except in trifluoroethanol, where a weak fluorescence could be detected (Table 1). As fluorescence is the main technique we used to study the excited-state properties, we have no direct information on the fate of 45 excited 1-NMe in these media. Nevertheless, based on the behaviour of structurally related molecules, we will propose a hypothesis for the lack of fluorescence.

The most stable structure of $\mathbf{1 - N M e}$ is probably that depicted in Scheme 3 as the planar $\mathbf{N}_{\mathbf{p}}$ form or its 50 conformational isomer with $180^{\circ}$ rotation around the interannular bond. They both present an intramolecular hydrogen bond between the hydroxyl group and the imidazole nitrogen. Taking into account the known photoacid character of the hydroxyl group and the behaviour of a large number of ${ }_{55}$ similar molecules, ${ }^{1-5} \mathbf{N}_{\mathbf{p}}^{*}$ probably experiences an ultrafast ESIPT process to yield the tautomeric form $\mathbf{T}_{\mathbf{p}}^{*}$ (Scheme 3 ). We hypothesize that this species is non-emissive. This assumption is based on the behaviour that we and others have found for related hydroxyphenylazoles. The experiments 60 showed that these molecules experience a viscosity-dependent radiationless deactivation most probably associated with a large-amplitude conformational change. ${ }^{28-36,41-43,46-52}$ This change is likely to be connected with a charge migration in the phototautomer originated by the previous excited-state ${ }_{65}$ intramolecular proton transfer, leading to a non-emissive charge-transfer species. ${ }^{31-36,}$ 47-50 Quantum mechanical calculations on several related molecules have shown that the excited tautomer possesses minimum energy at a twisted (and pyramidalized in many cases) geometry, its conformational 70 relaxation and subsequent ultrafast internal conversion being responsible for the fast decay of the phototautomer. ${ }^{30-34,36,46-}$ ${ }^{48,50-52} \mathrm{~A} \mathrm{~S}_{0} / \mathrm{S}_{1}$ conical intersection at the twisted geometry of the tautomer was found in some cases, ${ }^{30,36,46,52}$ but not in others. $^{50}$ According to these results, we hypothesize for 75 1-NMe that after ESIPT a charge-transfer process from the phenoxy ring to the protonated imidazopyridine moiety occurs (Scheme 3), leading to a twisted (and probably pyramidalized) TICT structure of biradicaloid nature, $\mathbf{T}_{\mathbf{p}}^{*}(\mathbf{C T})$, responsible for the ultrafast radiationless deactivation of 1-NMe.

80 Under the above hypothesis, the weak fluorescence detected for 1-NMe in trifluoroethanol solution must be due to the existence in this solvent of detectable amounts of groundstate conformers of $\mathbf{N}_{\mathbf{p}}$ which lack the intramolecular hydrogen bond ( $\mathbf{N}_{\mathbf{p}-\text { open }}$, Scheme 3 ), thus preventing the 85 occurrence of the ESIPT-TICT process and allowing fluorescence to compete successfully. The high hydrogenbond donor ability $\alpha$ of trifluoroethanol (see Table 3 ) would facilitate the formation of a strong hydrogen bond of the solvent with imidazole nitrogens, breaking the intramolecular 90 hydrogen bond of 1-NMe. We must suppose nevertheless that the $\mathbf{N}_{\mathbf{p} \text {-open }}$ conformers would also exist in water or other alcohols, as they have strong hydrogen-bond acceptor ability $\beta$ in addition to fairly high $\alpha$ values, thus facilitating the formation of several intermolecular hydrogen bonds of the 95 solute with the hydroxylic solvent molecules (see Scheme 3 ). Taking into account that water and ethanol have a higher capacity to accept a proton from the solute than trifluoroethanol, we interpret the lack of fluorescence for 1-NMe open conformers in these solvents as being due to its 100 dissociation taking place in the excited state, affording the 


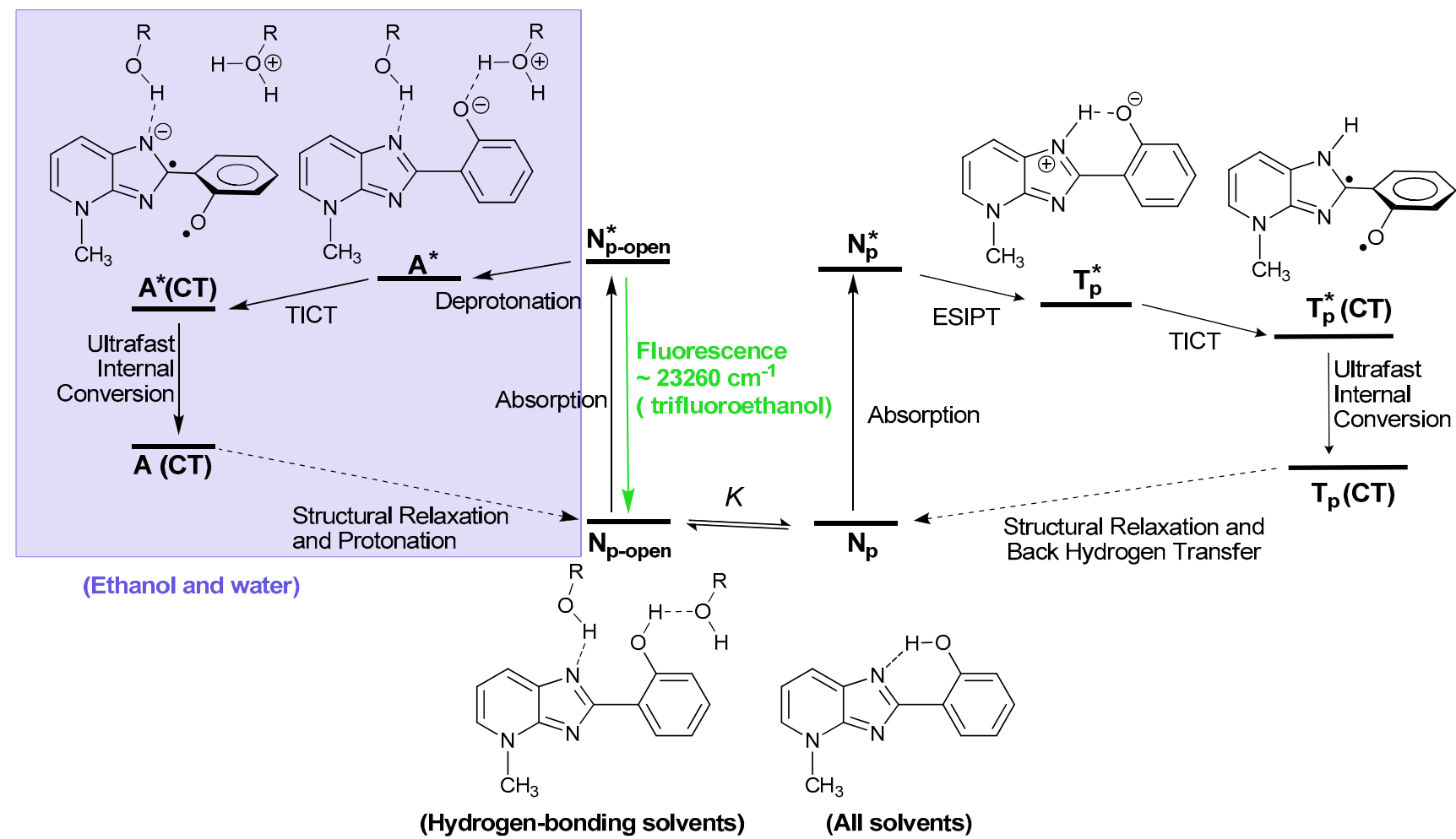

Scheme 3 Excitation and deactivation pattern proposed for 1-NMe in neutral media.

excited anion $\mathbf{A}^{*}$ in water and ethanol. As we have shown

5 (Table 3), the 1-NMe anion is non-fluorescent, probably also due to a TICT process affording the charge transfer state A*(CT), facilitated by the negative charge on the electron donor moiety (see Scheme 3). Similar excited-state dissociation of the open conformers of ESIPT dyes in 10 hydrogen-bonding solvents has been found in many cases, ${ }^{28,}$ 45, 65, 76, 79 causing in TICT-prone molecules an increase in the radiationless deactivation. ${ }^{28}$

\subsection{Excited-state behaviour of 1-NMe in acidic solutions:} ESIPT and Photodissociation

15 1-NMe exhibited quite intense fluorescence emission in acidified acetonitrile and trifluoroethanol, which overlapped the absorption band (see Fig. 4 and Table 1). The excitation and emission spectra were independent of the monitoring wavenumber and the fluorescence decay was 20 monoexponential in acetonitrile at any wavenumber (Table 2), indicating that a unique species is responsible for the fluorescence emission. Nevertheless, in addition to the ground-state precursor of the only fluorescent species, at least another non-fluorescent cation must be present in acidified ${ }_{25}$ acetonitrile and trifluoroethanol solutions, as the fluorescence excitation spectrum did not match the absorption spectrum (Fig. 4).

Fig. 9 illustrates the possible configurations of protonated 1-NMe. Two non-equivalent imidazole positions are available 30 for the proton $(1 H$ and $3 H)$, and each isomer may have the hydroxyl group in syn or anti position with respect to the pyridine nitrogen. From the four resulting isomers, two may form an intramolecular hydrogen bond $\mathrm{N} \cdots \mathrm{H}-\mathrm{O}$, and the other two an $\mathrm{N}-\mathrm{H} \cdots \mathrm{OH}$ bond. We may suppose that the isomers 35 with intramolecular hydrogen bond $\mathrm{N} \cdots \mathrm{H}-\mathrm{O}$ probably experience an ultrafast ESIPT from the hydroxyl group to the nitrogen upon excitation $\left(\mathbf{C}_{\mathbf{p}} \mathbf{1} \boldsymbol{H}_{\text {syn }}^{*}\right.$ and $\mathbf{C}_{\mathbf{p}} \mathbf{3} \boldsymbol{H}_{\text {anti }}^{*}$ would originate the tautomeric cations $\mathbf{T} \mathbf{C}_{\boldsymbol{s} y \boldsymbol{n}}^{*}$ and $\left.\mathbf{T} \mathbf{C}_{\text {anti }}^{*}\right)$. Based on the behaviour discussed above in section 4.4 for neutral 40 1-NMe, we hypothesize that the high positive charge on the imidazopyridine ring of the tautomeric cations triggers a charge-transfer process from the phenoxy ring to the protonated imidazopyridine ring, this process leading to a non-emissive twisted structure ( $\mathbf{T C}_{\text {anti }}^{*}(\mathbf{C T})$ in Scheme 4). We ${ }_{45}$ may assume therefore that $\mathbf{T} \mathbf{C}_{\text {syn }}^{*}$ and $\mathbf{T} \mathbf{C}_{\text {anti }}^{*}$ are nonfluorescent species, and that one or both of its precursors $\mathrm{C}_{\mathrm{p}} \mathbf{1} \boldsymbol{H}_{\text {syn }}^{*}$ and $\mathbf{C}_{\mathrm{p}} \mathbf{3} \boldsymbol{H}_{\text {anti }}^{*}$ would be responsible for the absorption bands of 1-NMe in acidified acetonitrile and trifluoroethanol solutions that do not produce detectable ${ }_{50}$ fluorescence emission (see Fig. 4). The absence of a large Stokes-shifted band in the fluorescence spectrum of cationic 1-NMe supports this interpretation, as this type of band is characteristic of the emission of molecules after ESIPT.

On the basis of the previous analysis, one of the species ${ }_{55} \mathbf{C}_{\mathbf{p}} \mathbf{3} \boldsymbol{H}_{\text {syn }}^{*}$ or $\mathbf{C}_{\mathbf{p}} \mathbf{1} \boldsymbol{H}_{\text {anti }}^{*}$, with intramolecular hydrogen bond $\mathrm{N}-\mathrm{H} \cdots \mathrm{OH}$ and precluded ESIPT, must be responsible for the fluorescent emission of protonated 1-NMe in acetonitrile and trifluoroethanol. The monoexponential decays monitored at several emission wavenumbers indicate that probably one of 60 them is in much greater concentration than the other, but the fluorescence measurements do not allow a more concrete assignment. 

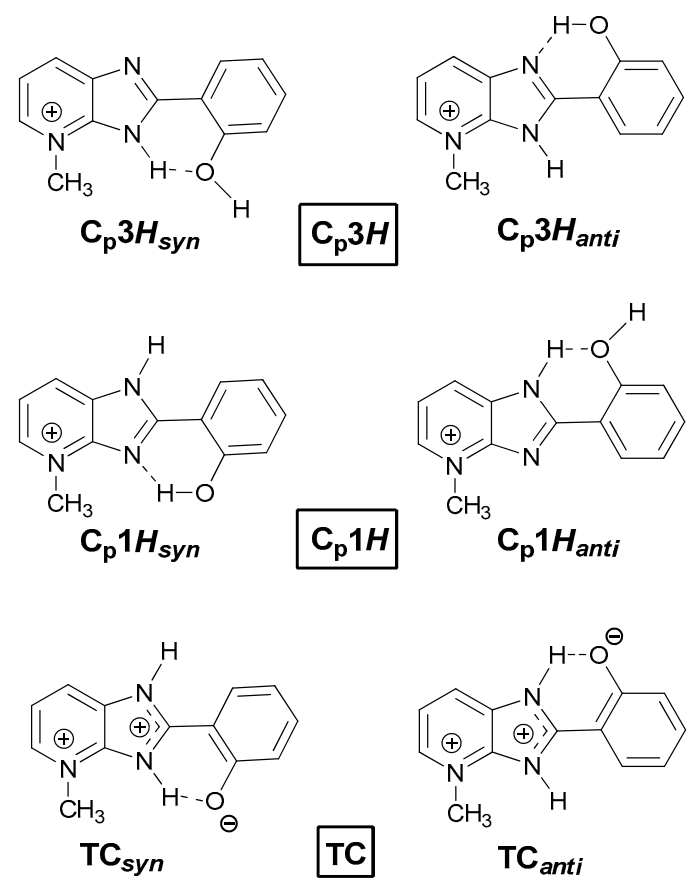

Fig. 9 Molecular structures of several isomers of 1-NMe cation. Hydrogen-bonded conformers and tautomers of the pyridinium cation $\left(\mathbf{C}_{\mathbf{p}}\right)$ and tautomeric cation (TC) obtained after ESIPT are shown. $1 H$ and $3 H$ indicate the site of the imidazole hydrogen, whilst syn and 5 anti indicate the relative positions of the oxygen atom and the pyridine nitrogen.

By contrast with the behaviour in acetonitrile and trifluoroethanol, no fluorescence could be detected for 1-NMe 10 in acidified ethanol and water with $25 \%$ EtOH. In these solvents, the tautomeric cations $\mathbf{T C}$, probably formed by ESIPT in $\mathbf{C}_{\mathbf{p}} \mathbf{1} \boldsymbol{H}_{\text {syn }}^{*}$ or $\mathbf{C}_{\mathbf{p}} \mathbf{3} \boldsymbol{H}_{\text {anti }}^{*}$ as in acetonitrile and trifluoroethanol, would be likewise non-emissive. The different behaviour must come then from the lack of emission 15 of $\mathbf{C}_{\mathbf{p}} \mathbf{3} \boldsymbol{H}_{\boldsymbol{s y n}}^{*} / \mathbf{C}_{\mathbf{p}} \mathbf{1} \boldsymbol{H}_{\boldsymbol{a n t i}}^{*}$ in ethanol and water. It is unlikely that this fact is due to these species being in very low concentration in the ground state in ethanol and water, as it is well known from related systems that the high hydrogen-bond ability of these solvents favour the species with the weaker 20 intramolecular hydrogen bond $\mathrm{N}-\mathrm{H} \cdots \mathrm{OH}, \quad \mathbf{C}_{\mathbf{p}} \mathbf{3} \boldsymbol{H}_{\text {syn }}$ and $\mathbf{C}_{\mathrm{p}} \mathbf{1} \boldsymbol{H}_{\text {anti }}{ }^{65,}{ }^{76,85}$ Comparison of the properties of the solvents studied led us to conclude that the negligible basicity of acetonitrile and trifluoroethanol is most likely the common characteristics of these solvents affecting the fluorescence ${ }_{25}$ properties of 1-NMe, as the polarity is similar for acetonitrile and the alcohols, and the capacity to donate a hydrogen bond is similar for trifluoroethanol and water. The striking difference in the fluorescence behaviour of 1-NMe in acetonitrile/trifluoroethanol and ethanol/water is then 30 probably due to the capacity of the last solvents to act as bases, accepting a proton from the solute. This capacity must be related to the known increase in acidity of the hydroxyl group upon excitation, especially for protonated derivatives of aromatic alcohols. The cations of several molecules 35 structurally related to $\mathbf{1 - N M e}$ behave as very strong photoacids in proton-accepting solvents, yielding the neutral tautomer. ${ }^{65,76,80,85-87}$ We hypothesize that protonated 1-NMe experiences also a fast dissociation in the excited state, generating the neutral tautomer $\mathbf{T}_{\mathbf{p}}^{*}$ (Scheme 4). As we stated 40 in the previous section, this species probably has a negligible fluorescence.

Our global interpretation of the fluorescence behaviour of protonated 1-NMe is summarized in Scheme 4. A groundstate equilibrium between isomers with intramolecular 45 hydrogen bond $\mathrm{N} \cdots \mathrm{H}-\mathrm{O}$ and $\mathrm{N}-\mathrm{H} \cdots \mathrm{OH}$ exist (to simplify the figure, we have depicted in Scheme 4 only the species $\mathrm{C}_{\mathrm{p}} \mathbf{1} \boldsymbol{H}_{\text {anti }}$ and $\mathrm{C}_{\mathrm{p}} \mathbf{3} \boldsymbol{H}_{\text {anti }}$, but similar behaviour is expected for the species $\mathbf{C}_{\mathrm{p}} \mathbf{3} \boldsymbol{H}_{\text {syn }}$ and $\mathbf{C}_{\mathrm{p}} \mathbf{1} \boldsymbol{H}_{\text {syn }}$; we don't have information about the main isomers present in solution). The molecules 50 with $\mathrm{N} \cdots \mathrm{H}-\mathrm{O}$ intramolecular hydrogen bond undergo an ESIPT-TICT process upon excitation, which results in a fast radiationless deactivation. The molecules with $\mathrm{N}-\mathrm{H} \cdots \mathrm{OH}$ intramolecular hydrogen bond and precluded ESIPT would either deactivate and emit fluorescence, or rapidly dissociate 55 in proton-accepting solvents. The dissociated species would originate a non-emissive TICT state.

\section{Conclusions}

We have synthesized the novel ESIPT dye 1-NMe, whose fluorescence is undetectable in neutral media, except in ${ }_{60}$ hydrogen-bonding and very weakly basic solvents like trifluoroethanol, where it shows a feeble fluorescence. This fact indicates a very efficient radiationless deactivation of the first-excited singlet state. Based on the behaviour of similar molecules, we propose that upon excitation, 1-NMe ${ }_{65}$ experiences an ultrafast ESIPT process to form a protontransferred tautomeric species, which would undergo a TICT process and consequent very fast radiationless deactivation. The fraction of ground-state tautomers intermolecularly hydrogen bonded to the solvent would deprotonate and 70 experience afterwards also a TICT process and fast radiationless deactivation. The exception would be trifluoroethanol, due to the inability of this solvent to accept the photodissociated proton, which allows observing the fluorescence of the small fraction of open tautomers in this 75 solvent. The very efficient excited-state deactivation of 1-NMe suggests that this kind of structure could be useful as a new family of UV photoprotectors.

We have found that protonation of 1-NMe takes place at one of the benzimidazole nitrogens. The cation shows intense 80 fluorescence in acetonitrile and trifluoroethanol, but is nonemissive in ethanol and water. We interpret these facts as being due to the photoacid properties of 1-NMe cation and the different basicities of these solvents. The tautomers of cationic 1-NMe with a $\mathrm{N}-\mathrm{H} \cdots \mathrm{OH}$ intramolecular hydrogen 85 bond would behave as strong photoacids, rapidly dissociating at the hydroxyl group in solvents like water and ethanol and giving rise to the non-fluorescent neutral species. On the contrary, the same tautomers would decay by fluorescence emission and radiationless deactivation in solvents like 90 acetonitrile and trifluoroethanol, unable to accept the proton. Moreover, the absence of fluorescence from a protontransferred form for cationic 1-NMe indicates that the tautomers with intramolecular hydrogen bond $\mathrm{N} \cdots \mathrm{H}-\mathrm{O}$ most 


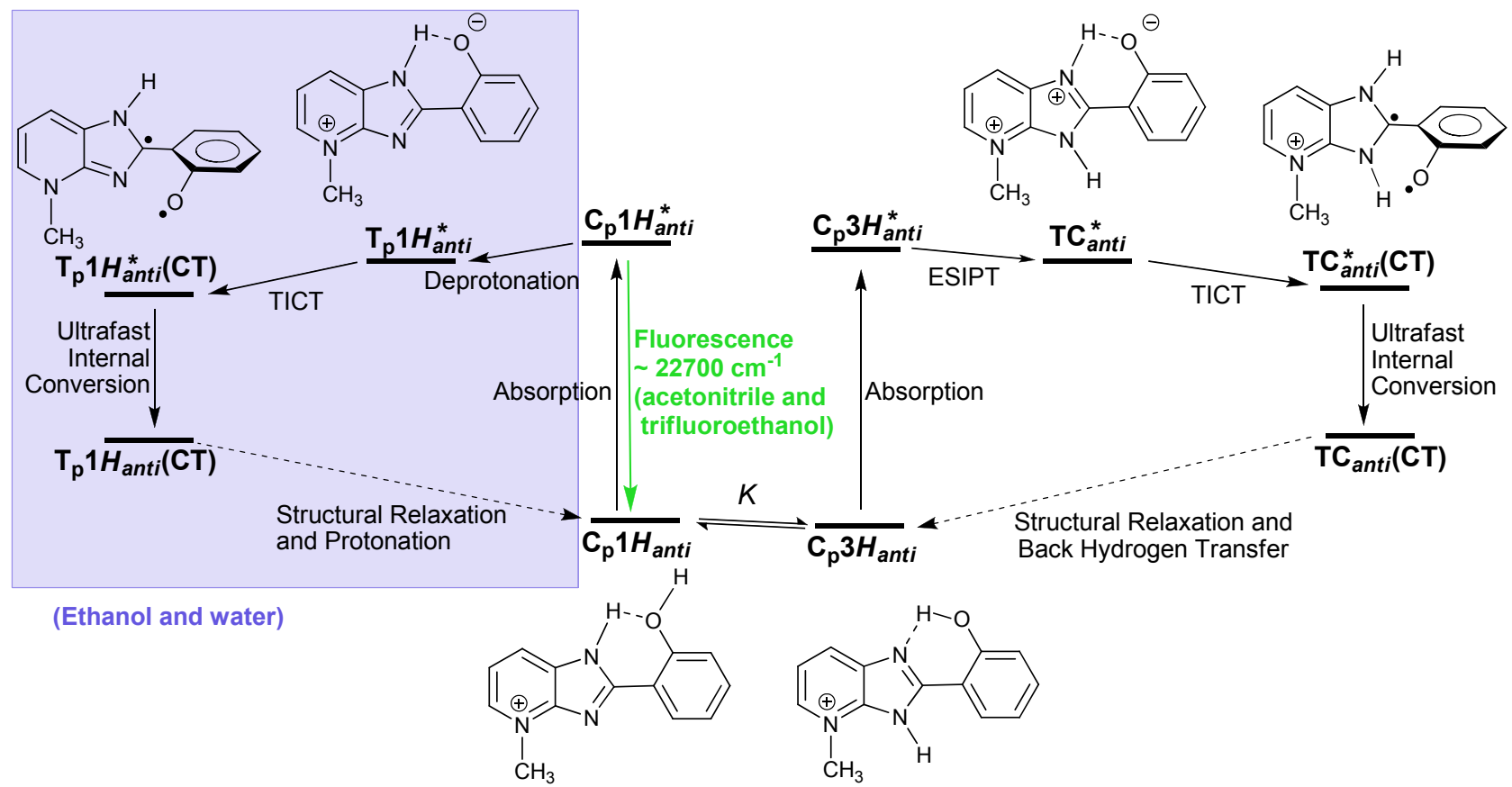

Scheme 4 Excitation and deactivation pattern proposed for 1-NMe in acidic solutions. A similar mechanism is expected for the ground-state species $\mathbf{C}_{\mathrm{p}} 3 \boldsymbol{H}_{\text {syn }} / \mathbf{C}_{\mathrm{p}} \mathbf{1} \boldsymbol{H}_{\text {syn }}$

probably experience an ESIPT-TICT process, causing a very 5 fast radiationless deactivation of those conformers in all the solvents examined.

Excitation of neutral 1-OMe in acetonitrile, ethanol, and water lead to its own emission. However, a large fraction of 1-OMe molecules gets protonated at the pyridine nitrogen in 10 trifluoroethanol, which proves its strong photobasic properties.

Protonation of 1-OMe takes place at the imidazole and pyridine nitrogens. The presence of the two cations in the ground state was detected in all of the solvents studied, the 15 pyridinium cation being always the main component. The amount of the imidazolium cation is increased when the hydrogen-bond donor ability of the solvent increases. The absorption and fluorescence spectra of the two cations are strongly overlapped. We devised a method to resolve the

20 overlapping spectra by applying a principal component global analysis to a series of excitation spectra taken at different monitoring emission wavenumbers. In the analysis, we assumed that the coefficients presented a log-normal dependence with the external parameter (monitoring emission 25 wavenumbers). This procedure allowed us to resolve the components of the absorption and fluorescence spectra of cationic 1-OMe and estimate the equilibrium constant between the cations in several solvents. The method developed could be useful for other cases of overlapping 30 structureless spectra of fluorescent species in equilibrium.

\section{Acknowledgements}

We are indebted to the Spanish Ministry of Education and Science and the European Regional Development Fund (Grants CTQ2007-68057-C02-01/BQU and CTQ201035 17835) and the Xunta de Galicia (Grant IN845B-2010/094) for financial support of our work. A. Brenlla thanks the Fundación Segundo Gil Dávila for a postgraduate research grant.

\section{Notes and references}

$4^{a}$ Departamento de Química Física e Centro Singular de Investigación en Química Biolóxica e Materiais Moleculares, Universidade de Santiago de Compostela, E-15782 Santiago de Compostela, Spain. E-mail:

carmen.rios@usc.es,manuel.mosquera@usc.es, flor.rodriguez.prieto@usc.es.

451 S. J. Formosinho and L. G. Arnaut, J. Photochem. Photobiol. A, 1993, 75, 21-48.

2 S. M. Ormson and R. G. Brown, Prog. React. Kinet., 1994, 19, $45-$ 91.

3 T. Elsaesser and H. J. Bakker, Ultrafast Hydrogen Bonding 50 Dynamics and Proton Transfer Processes in the Condensed Phase, Kluwer Acad. Pub., Dordrecht, 2002.

4 J. T. Hynes, J. T. Klinman, H. H. Limbach and R. L. Schowen, Hydrogen-Transfer Reactions, Wiley-VCH, Weinheim, 2007.

5 K.-L. Han and G.-J. Zhao eds., Hydrogen Bonding and Transfer in 55 the Excited State, Wiley, Chichester, 2010.

6 N. Mataga, H. Chosrowjan and S. Taniguchi, J. Photochem. Photobiol. C, 2005, 6, 37-79.

7 Z. R. Grabowski, K. Rotkiewicz and W. Rettig, Chem. Rev., 2003, 103, 3899-4031.

608 V. Volchkov and B. Uzhinov, High Energy Chem., 2008, 42, 153169.

9 S. Scheiner, J. Phys. Chem. A, 2000, 104, 5898-5909.

10 C. H. Kim and T. Joo, Phys. Chem. Chem. Phys., 2009, 11, 1026610269.

6511 F. Y. Dupradeau, D. A. Case, C. Z. Yu, R. Jimenez and F. E. Romesberg, J. Am. Chem. Soc., 2005, 127, 15612-15617. 
12 Q. Chu, D. A. Medvetz and Y. Pang, Chem. Mat., 2007, 19, 64216429.

13 A. P. deSilva, H. Q. N. Gunaratne, T. Gunnlaugsson, A. J. M. Huxley, C. P. McCoy, J. T. Rademacher and T. E. Rice, Chem. Rev., 5 1997, 97, 1515-1566.

14 J. F. Callan, A. P. de Silva and D. C. Magri, Tetrahedron, 2005, 61, 8551-8588.

15 B. Valeur and I. Leray, Coord. Chem. Rev., 2000, 205, 3-40.

16 S. Park, S. Kim, J. Seo and S. Y. Park, Macromol. Res., 2008, 16, 10 385-395.

17 S. Park, J. E. Kwon, S. H. Kim, J. Seo, K. Chung, S. Y. Park, D. J. Jang, B. M. Medina and J. Gierschner, J. Am. Chem. Soc., 2009, 131, 14043-14049.

18 K. Jayaramulu, P. Kanoo, S. J. George and T. K. Maji, Chem. 15 Commun., 2010, 46, 7906-7908.

19 C. C. Hsieh, C. M. Jiang and P. T. Chou, Acc. Chem. Res., 2010, 43, 1364-1374.

20 C. C. Hsieh, M. L. Ho and P. T. Chou, in Advanced Fluorescence Reporters in Chemistry and Biology I: Fundamentals and Molecular

20 Design, ed. A. P. Demchenko, Springer-Verlag, Berlin, 2010, pp. 225266.

21 D. Gormin and M. Kasha, Chem. Phys. Lett., 1988, 153, 574-576.

22 A. Sytnik, D. Gormin and M. Kasha, Proc. Natl. Acad. Sci. U. S. A., 1994, 91, 11968-11972.

2523 S. M. Ormson, R. G. Brown, F. Vollmer and W. Rettig, J. Photochem. Photobiol. A, 1994, 81, 65-72.

24 P. T. Chou, M. L. Martinez and J. H. Clements, J. Phys. Chem., 1993, 97, 2618-2622.

25 C. C. Hsieh, Y. M. Cheng, C. J. Hsu, K. Y. Chen and P. T. Chou, J. 30 Phys. Chem. A, 2008, 112, 8323-8332.

26 J. Seo, S. Kim and S. Y. Park, J. Am. Chem. Soc., 2004, 126, $11154-$ 11155.

27 C. H. Kim, J. Park, J. Seo, S. Y. Park and T. Joo, J. Phys. Chem. A, 2010, 114, 5618-5629.

3528 A. Maliakal, G. Lem, N. J. Turro, R. Ravichandran, J. C. Suhadolnik, A. D. DeBellis, M. G. Wood and J. Lau, J. Phys. Chem. A, 2002, 106, 7680-7689.

29 J. C. Suhadolnik, A. D. DeBellis, C. Hendricks-Guy, R. Iyengar and M. G. Wood, J. Coat. Technol., 2002, 74, 55-61.

4030 M. J. Paterson, M. A. Robb, L. Blancafort and A. D. DeBellis, J. Am. Chem. Soc., 2004, 126, 2912-2922.

31 C. A. S. Potter, R. G. Brown, F. Vollmer and W. Rettig, J. Chem. Soc., Faraday Trans., 1994, 90, 59-67.

32 F. Vollmer and W. Rettig, J. Photochem. Photobiol. A, 1996, 95, 45 143-155.

33 D. LeGourriérec, V. Kharlanov, R. G. Brown and W. Rettig, J. Photochem. Photobiol. A, 1998, 117, 209-216.

34 S. Kim, J. Seo and S. Y. Park, J. Photochem. Photobiol. A, 2007, 191, 19-24.

5035 S. Ríos Vázquez, M. C. Ríos Rodríguez, M. Mosquera and F. Rodríguez-Prieto, J. Phys. Chem. A, 2007, 111, 1814-1826.

36 H.-H. G. Tsai, H.-L. S. Sun and C.-J. Tan, J. Phys. Chem. A, 2010, 114, 4065-4079.

37 M. H. V. Huynh and T. J. Meyer, Chem. Rev., 2007, 107, 5004-5064. 5538 S. Hammes-Schiffer and A. V. Soudackov, J. Phys. Chem. B, 2008, 112, 14108-14123.
39 N. A. Shaath, Photochem. Photobiol. Sci., 2010, 9, 464-469.

40 A. P. Fluegge, F. Waiblinger, M. Stein, J. Keck, H. E. A. Kramer, P. Fischer, M. G. Wood, A. D. DeBellis, R. Ravichandran and D. Leppard, 60 J. Phys. Chem. A, 2007, 111, 9733-9744.

41 P. F. Barbara, L. E. Brus and P. M. Rentzepis, J. Am. Chem. Soc., 1980, 102, 5631-5635.

42 W. Al-Soufi, K. H. Grellmann and B. Nickel, Chem. Phys. Lett., 1990, 174, 609-616.

6543 W. E. Brewer, M. L. Martinez and P. T. Chou, J. Phys. Chem., 1990, 94, 1915-1918.

44 Y. Nosenko, G. Wiosna-Salyga, M. Kunitski, I. Petkova, A. Singh, W. J. Buma, R. P. Thummel, B. Brutschy and J. Waluk, Angew. Chem.Int. Edit., 2008, 47, 6037-6040.

7045 R. S. Becker, C. Lenoble and A. Zein, J, Phys. Chem., 1987, 91, 3509-3517.

46 A. L. Sobolewski, W. Domcke and C. Hattig, J. Phys. Chem. A, 2006, 110, 6301-6306.

47 D. LeGourriérec, V. A. Kharlanovb, R. G. Brown and W. Rettig, J. 75 Photochem. Photobiol. A, 2000, 130, 101-111.

48 M. I. Knyazhansky, A. V. Metelitsa, A. J. Bushkov and S. M. Aldoshin, J. Photochem. Photobiol. A, 1996, 97, 121-126.

49 S. Ríos Vázquez, M. C. Ríos Rodríguez, M. Mosquera and F. Rodríguez-Prieto, J. Phys. Chem. A, 2008, 112, 376-387.

8050 F. A. S. Chipem and G. Krishnamoorthy, J. Phys. Chem. A, 2009, 113, 12063-12070.

51 C. M. Estevez, R. D. Bach, K. C. Hass and W. F. Schneider, J. Am. Chem. Soc., 1997, 119, 5445-5446.

52 M. Barbatti, A. J. A. Aquino, H. Lischka, C. Schriever, S. 85 Lochbrunner and E. Riedle, Phys. Chem. Chem. Phys., 2009, 11, 14061415.

53 A. O. Doroshenko, E. A. Posokhov, A. A. Verezubova, L. M. Ptyagina, V. T. Skripkina and V. M. Shershukov, Photochem. Photobiol. Sci., 2002, 1, 92-99.

9054 N. Dash, F. A. S. Chipem, R. Swaminathan and G. Krishnamoorthy, Chem. Phys. Lett., 2008, 460, 119-124.

55 S. H. Yin, Y. F. Liu, W. Zhang, M. X. Gu and P. Song, J. Comput. Chem., 2010, 31, 2056-2062.

56 US Pat., 6936618 B2, 2005.

9557 W. J. Coates, B. Connolly, D. Dhanak, S. T. Flynn and A. Worby, J. Med. Chem., 1993, 36, 1387-1392.

58 V. Bavetsias, C. Sun, N. Bouloc, J. Reynisson, P. Workman, S. Linardopoulos and E. McDonald, Bioorg. Med. Chem. Lett., 2007, 17, 6567-6571.

10059 S. K. Das and S. K. Dogra, J. Chem. Soc., Perkin Trans. 2, 1998, 2765-2771.

60 P. Barraclough, D. Firmin, R. Iyer, W. R. King, J. C. Lindon, M. S. Nobbs, S. Smith, C. J. Wharton and J. M. Williams, J. Chem. Soc.-Perkin Trans. 2, 1988, 1839-1846.

10561 W. H. Melhuish, J. Phys. Chem., 1961, 65, 229-235.

62 G. A. Crosby and J. N. Demas, J. Phys. Chem., 1971, 75, 991-1024.

63 F. Rodríguez Prieto, M. Mosquera and M. Novo, J. Phys. Chem., 1990, 94, 8536-8542.

64 M. Novo, M. Mosquera and F. Rodriguez Prieto, Can. J. Chem., $1101992, \mathbf{7 0}, 823-827$.

65 M. Mosquera, J. C. Penedo, M. C. Ríos Rodríguez and F. RodríguezPrieto, J. Phys. Chem., 1996, 100, 5398-5407. 
66 W. Al-Soufi, M. Novo and M. Mosquera, Appl. Spectrosc., 2001, 55, 630-636.

67 M. J. Kamlet, J. L. M. Abboud, M. H. Abraham and R. W. Taft, J. Org. Chem., 1983, 48, 2877-2887.

568 M. Novo, M. Mosquera and F. Rodríguez Prieto, J. Phys. Chem., 1995, 99, 14726-14732.

69 R. Yang and S. G. Schulman, Luminescence, 2001, 16, 129-133.

70 E. Bardez, A. Chatelain, B. Larrey and B. Valeur, Journal of Physical Chemistry, 1994, 98, 2357-2366.

1071 D. B. Siano and D. E. Metzler, Journal of Chemical Physics, 1969, 51, 1856-1861.

72 B. Valeur, Molecular Fluorescence: Principles and Applications, Wiley-VCH, Weinheim (Germany), 2002.

73 Z. R. Grabowski and A. Grabowska, Z. Physik. Chem. Neue Folge, 15 1976, 101, 197-208.

74 A. Douhal, F. Amat-Guerri, M. P. Lillo and A. U. Acuna, J. Photochem. Photobiol. A, 1994, 78, 127-138.

75 G. Krishnamoorthy and S. K. Dogra, J. Lumines., 2000, 92, 103-114.

76 M. C. Ríos Rodríguez, F. Rodríguez-Prieto and M. Mosquera, Phys.

${ }_{20}$ Chem. Chem. Phys., 1999, 1, 253-260.

77 J. Durmis, M. Karvaš and Z. Maňásek, Collect. Czech. Chem. Commun., 1973, 38, 224-242.

78 J. Catalán, E. Mena, F. Fabero and F. Amat-Guerri, J. Chem. Phys., 1992, 96, 2005-2016.

2579 F. Rodriguez-Prieto, J. C. Penedo and M. Mosquera, J. Chem. Soc., Faraday Trans., 1998, 94, 2775-2782.

80 M. Mosquera, M. C. Ríos Rodríguez and F. Rodríguez-Prieto, J. Phys. Chem. A, 1997, 101, 2766-2772.

81 J. Waluk, Acc. Chem. Res., 2003, 36, 832-838.

3082 D. R. Lide, Handbook of Chemistry and Physics, CRC Press LLC, Boca Raton, 2004

83 N. Agmon, J. Phys. Chem. A, 2005, 109, 13-35

84 L. M. Tolbert and K. M. Solntsev, Acc. Chem. Res., 2002, 35, 19-27.

85 A. Brenlla, F. Rodríguez-Prieto, M. Mosquera, M. A. Ríos and M. C.

35 Ríos Rodriguez, J. Phys. Chem. A, 2009, 113, 56-67.

86 J. C. Penedo, M. Mosquera and F. Rodríguez-Prieto, J. Phys. Chem. $A, 2000,104,7429-7441$.

87 M. Bräuer, M. Mosquera, J. L. Pérez-Lustres and F. RodríguezPrieto, J. Phys. Chem. A, 1998, 102, 10736-10745. 